\title{
Sonoproduction of Liposomes and Protein Particles as Templates for Delivery Purposes
}

\author{
Raquel Silva, ${ }^{\dagger}$ Helena Ferreira, ${ }^{\dagger,}$ and Artur Cavaco-Paulo ${ }^{*}, \dagger$ \\ ${ }^{\dagger}$ Department of Textile Engineering, Campus de Azurém, University of Minho, 4800-058, Guimarães, Portugal \\ ${ }^{\ddagger}$ Health Sciences Research Sciences, Department of Pharmaceutical Sciences, CICS, Rua Central de Gandra, 1317, 4585-116 \\ Gandra-PRD, Portugal
}

ABSTRACT: The development of nano and micro delivery systems (DS), so small in size, is growing in importance, such as in drug targeting. In an era where nano is the new trend, micro and nano materials are in the forefront of progress. These systems can be produced by a diversity of methods. However, the use of high-intensity ultrasound offers an easy and versatile tool for nano- and microstructured materials that are often unavailable by conventional methods. Similarly to the

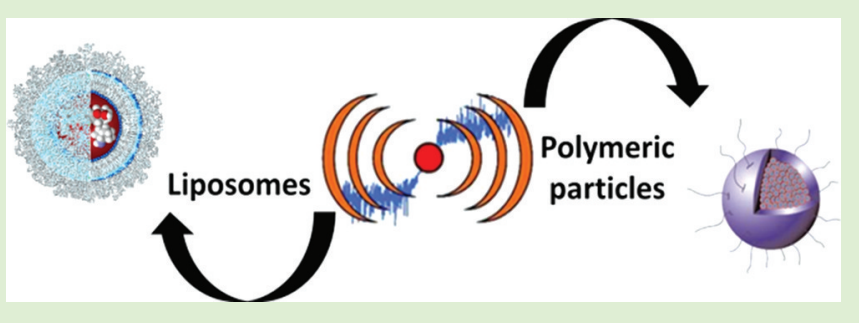
synthesis methods that can be used, several starting materials can be applied to produce particulate systems. In this review, the recent strategic development of DS is discussed with emphasis on liposomes and polymer-based, specially protein-based, nanomedicine platforms for drug delivery. Among the variety of applications that materials in the particulate form can have, the control release of drugs is probably the most prominent one, as these have been in the forefront line of interest for biomedical applications. The basic concepts of sonochemical process pertaining to DS are summarized as well as the role of sonochemical procedure to their preparation. The different applications of these systems wrap up this review.

\section{INTRODUCTION}

Nano- and microparticles are particulate delivery systems (DS) of nanometer or micrometer size ranges, respectively, and can incorporate therapeutic agents, such as small drugs or even macromolecules. ${ }^{1}$ The term microparticle refers to spherical particles with diameters range between 0.1 and $100 \mu \mathrm{m}$. Particles with diameter below $0.1 \mu \mathrm{m}$ are called nanoparticles. ${ }^{2}$

The promising significance of nano- and microparticles in the biomedical field and the needs of materials with biocompatibility, biodegradability, and nontoxicity have propelled the efforts for developing and optimizing new materials. Various types of particles like solid lipid nanoparticles, ${ }^{3}$ micelles, ${ }^{4}$ liposomes, ${ }^{5}$ dendrimers, ${ }^{6}$ and polymers ${ }^{7}$ have been reported as DS to encapsulate drugs and other bioactive agents (Figure 1).

Major advancements in delivery technology, such as particle size, drug encapsulation, and targeting optimization, have been achieved over the past few decades. Drug delivery, which takes into consideration the carrier, the route of administration, and the target, has evolved into a strategy of processes or devices designed to enhance the efficacy of therapeutic agents through controlled release. This may involve enhanced bioavailability, improved therapeutic index (ratio between the efficacy of the drug and its undesirable side effects), or improved patient acceptance or compliance. In fact, the administration of a drug in a DS influences their parameters, in particular concerning the pharmacokinetics and pharmacodynamics, which, in turn, affect their therapeutic index. ${ }^{8,9}$ Thus, the DS can increase the bioavailability of drugs and decrease their toxic effects, leading to an increase in therapeutic index (Figure 2). Additionally,

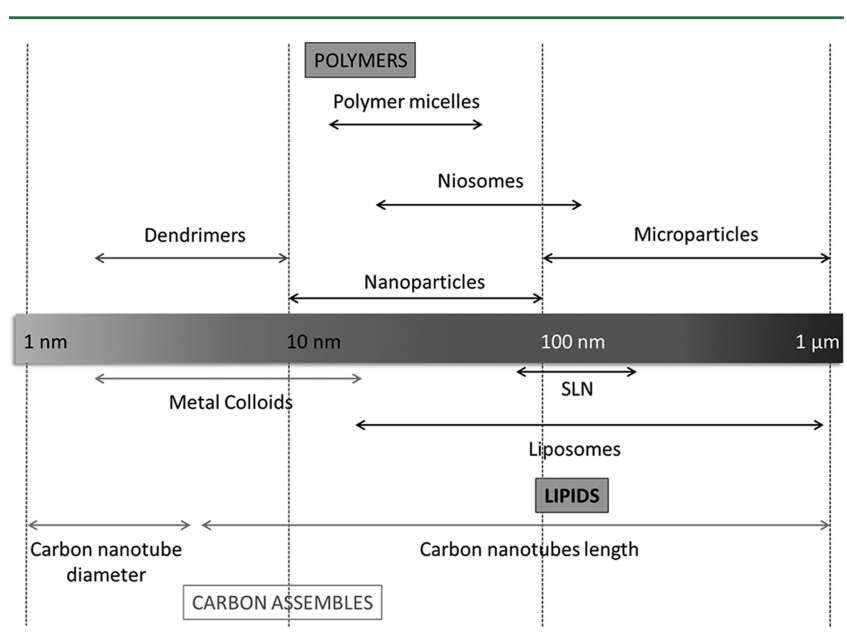

Figure 1. Types of nano- and microtechnology used for delivery purposes. The major components are either lipids or polymers. The black and gray axis represents the diameter of technology. Reproduced with permission from ref 8. Copyright 2006 Springer.

they can vehicular and release the drugs in a target cell, thereby decreasing the dose required to observe certain action, minimizing the side effects. ${ }^{10}$

The need of developing new DS at nano and microscaled materials is paralleled by attempts to optimize or develop new

Received: May 13, 2011

Revised: September 2, 2011

Published: September 9, 2011 


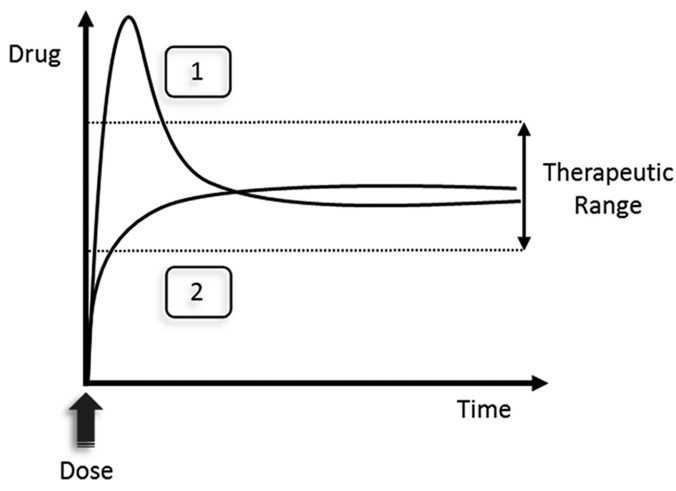

Figure 2. Release profile of conventional formulation (1) and drug delivery systems (DDS) (2) over time.

techniques to produce them. Therefore, numerous protocols exist for synthesizing nano and microparticles based on the type of drug used and the desired delivery route. Among a variety of approaches, the utilization of ultrasound for material synthesis has been extensively studied, and now is positioned as one of the most powerful tools in nano and micro structured materials synthesis. ${ }^{11}$ Once a protocol is chosen, the parameters must be tailored, such as time, agitation and geometry of reactor, to create the best possible characteristics for the developed particles.

In this review, the ultrasound-assisted synthetic methods (sonochemistry) will be discussed to provide a fundamental understanding of their basic principles and to demonstrate the powerful and unique aspects of ultrasound in nano and micro structured materials synthesis. This review also focuses on the materials-based drug delivery platform, highlighting the use of phospholipids and proteins. Finally, it will be pointing out to areas requiring focused effort to arrive at an understanding of applications of these devices as delivery systems in different biomedical applications.

\section{SONOCHEMISTRY}

Sonochemistry is the research area in which molecules can undergo a chemical reaction due to the application of powerful ultrasound radiation $(20 \mathrm{kHz}-10 \mathrm{MHz}) .{ }^{12}$ Considering typical sound velocities in liquids of $\approx 1500 \mathrm{~m} \mathrm{~s}^{-1}$, acoustic wavelengths range from 10 to $10^{-4} \mathrm{~cm}$, which is far above molecular and atomic dimensions. ${ }^{13}$ Thus, no direct molecular level interaction between ultrasound and chemical species take place. Instead, acoustic cavitation, driven by high-intensity ultrasound, accounts for the chemical effects of ultrasound. ${ }^{14}$ Ultrasonic irradiation differs from traditional energy sources in duration, pressure, and energy per molecule. ${ }^{13}$ Cavitation occurs over a very wide range of frequencies, from tens of hertz to tens of megahertz; above that frequency regime, the intrinsic viscosity of liquids prevents cavitation from occurring. Most high-intensity ultrasonic horns operate at 20 or $40 \mathrm{kHz}$, most cleaning baths near $40 \mathrm{kHz}$, and there is specialized equipment available in the few hundred kilohertz to few megahertz regime. $^{12,16}$ In general, physical effects of ultrasound (e.g., emulsification and surface damage) are more dominant at lower frequencies, whereas cavitational heating of collapsing bubbles occurs over the full frequency range. Acoustic cavitation appears in the liquids at high and moderate intensities of ultrasonic irradiation. The minimum power intensity required for ultrasonic cavitation increases with the increase of the frequency of ultrasound. ${ }^{17}$ When sonicating liquids at high intensities, the sound waves that propagate into the liquid media result in alternating high-pressure (compression) and low-pressure (rarefaction) cycles, with rates depending on the frequency. The liquid expands during the expansion by the sound field ("negative pressure", low pressure). This results in rapid growth of the weak sites of the liquid predominantly containing dissolved gases ("cavitation nuclei"), thus producing vapor- and gas-filled cavities or microbubbles. ${ }^{18}$ Then, the liquid compresses during the compression phase of the sound field ("positive pressure", high pressure). The bubbles continue to grow during the negative/positive cycles of the ultrasound until reaching a critical diameter (Figure 3), which depends on

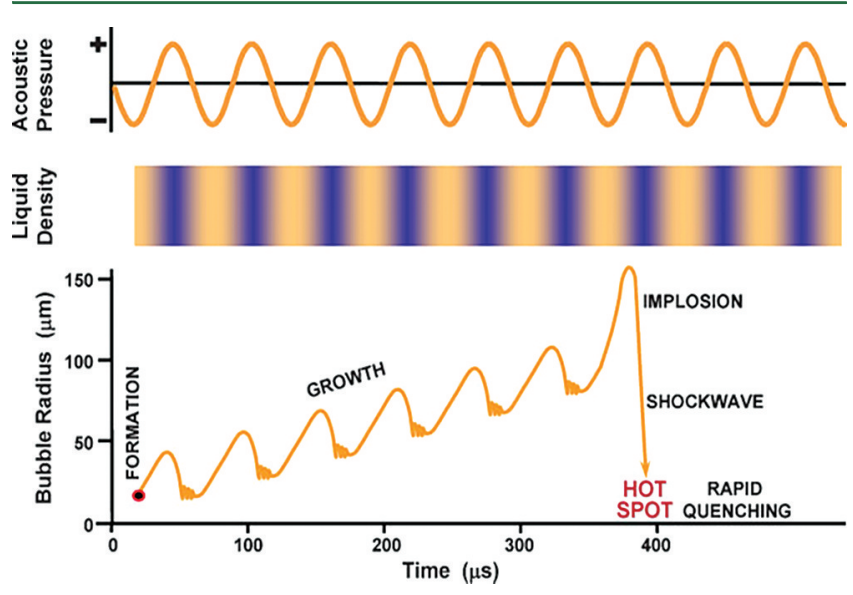

Figure 3. Schematic representation of transient acoustic cavitation. Reproduced with permission from ref 21. Copyright 1995 Cambridge University Press.

ultrasound frequency and nature of the liquid. This "critical" bubble is mostly filled with gases and vapor and thus unable to provide stiffness. The compression of bubbles occurring during cavitation is more rapid than thermal transport and generates localized hot spots. The compression of bubbles during cavitation leads to the enormous concentration of energy within the small volume of the collapsed bubble. The oscillating bubbles can accumulate ultrasonic energy effectively while growing to a certain size (typically tens of millimeters). ${ }^{19}$ Under the right conditions, a bubble can overgrow and subsequently collapse, releasing the concentrated energy stored in the bubble within a very short time (with a heating and cooling rate of $>10^{10} \mathrm{~K} \mathrm{~s}^{-1}$ ). This cavitational implosion is very localized and transient with a temperature of $\approx 5000 \mathrm{~K}$ and a pressure of $\approx 1000 \mathrm{bar}^{20}$

The chemical effects of ultrasound were explored for many years, specially in water. ${ }^{22-26}$ Ultrasonic irradiation of aqueous liquids generates free radicals and the formation of free radicals by sonolysis of water has been particularly well-studied. Primary sonolysis products in water are hydrogen radicals $\left(\mathrm{H}^{\bullet}\right)$ and hydroxyl radicals $\left({ }^{\bullet} \mathrm{OH}\right)$ (eq 1$) \cdot{ }^{27}$ These radicals can recombine to return to their original form or combine to produce hydrogen $\left(\mathrm{H}_{2}\right)$ and hydrogen peroxide $\left(\mathrm{H}_{2} \mathrm{O}_{2}\right)$ (eqs 2 and 3). They can also produce hydroperoxyl radicals $\left(\mathrm{HO}_{2}{ }^{\circ}\right)$ by combination with oxygen $\left(\mathrm{O}_{2}\right)$. These strong oxidants as well as the reductants are used for various sonochemical reactions in aqueous solutions.

$$
\begin{aligned}
& \mathrm{H}_{2} \mathrm{O} \rightarrow \mathrm{H}^{\bullet}+{ }^{\bullet} \mathrm{OH} \\
& \mathrm{H}^{\bullet}+\mathrm{H}^{\bullet} \rightarrow \mathrm{H}_{2}
\end{aligned}
$$




$$
\bullet \mathrm{OH}+{ }^{\bullet} \mathrm{OH} \rightarrow \mathrm{H}_{2} \mathrm{O}_{2}
$$

\subsection{Sonoproduction of Nano- and Microstructured} Materials. The ultrasonic irradiation, compared to traditional energy sources, provides rather unusual reaction conditions (a short duration of extremely high temperatures and pressures in liquids) that cannot be realized by other methods. ${ }^{18}$ Major developments in nanotechnology have been achieved, by sonochemistry methodology, synthesizing different nano- and microstructured materials. A diverse set of applications of ultrasound have been explored to obtain such different materials.

Table 1. Overview of the Materials Used To Achieve Different Nano- and Microstructures by Sonoproduction ${ }^{a}$

\begin{tabular}{|c|c|}
\hline material & type \\
\hline phospholipids & $\begin{array}{l}\text { liposomes (small unilamellar vesicles and large unilamellar } \\
\text { vesicles) }\end{array}$ \\
\hline triacylglycerols & solid lipid nanoparticles 43,44 \\
\hline polymers & $\begin{array}{l}\text { protein, }{ }^{45-70} \text { chitosan, }{ }^{71} \text { polyglutamate/ } \\
\text { polyethyleneimine/poly(acrylic acid), }{ }^{72} \text { poly(vinyl } \\
\left.\text { alcohol), },^{73} \text { poly(allylamine hydrochloride }\right) / \\
\text { polystyrenesulfonate, }{ }^{74,75} \text { gum acacia and } \text { starch }^{64} \text { nano- } \\
\text { and microparticles }\end{array}$ \\
\hline $\begin{array}{l}\text { inorganic } \\
\text { compounds }\end{array}$ & $\begin{array}{l}\text { nanoparticles, }{ }^{15,86-81} \text { nanotubes, }{ }^{82} \text { nanobelts, }{ }^{83,84} \\
\text { nanowires, }{ }^{85,86} \text { mesoporous and amorphous } \\
\text { nanostructured }\end{array}$ \\
\hline
\end{tabular}

${ }^{a}$ Information was compiled, in the scope of this review, from refs 15 and $28-88$.

Table 1 summarizes the most frequently used materials for the synthesis of nano- and microstructures by the sonochemical method.

Among all the materials used, liposomes and protein particles are widely used in biomedical field. For this reason, this review details the latest development of liposomes and protein nanoand microparticles DS and their potential applications.

\section{LIPOSOMES}

Liposomes are highly versatile structures for research therapeutic and analytical applications. ${ }^{89}$

Since Bangham et al. ${ }^{90}$ described for the first time the preparation of liposomes, they have been often used as membrane model systems to reveal the basic nature of cell membranes. In 1971, Gregoriadis ${ }^{91}$ proposed for the first time the use of liposomes as drug carrier systems, describing the conditions for the entrapment of Aspergillus niger amyloglucosidase (EC 3.2.1.3) and ${ }^{131}$ I-labeled albumin into liposomes composed of phosphatidylcholine, cholesterol, and dicetyl phosphate.

The unique physicochemical properties of liposomes coupled with a structural versatility explain the great potential of these resources organized as membrane models and vectors of drugs, which translate into huge numbers of studies achieved with these systems. $^{92}$

According to the parameters previously described, it is important to state the essential physicochemical characteristics along with their classification. Furthermore, an overview of liposomes preparation using the sonochemical methodology will be highlighted as well as their applications as DS.

3.1. Physicochemical Considerations. Phospholipids are the major structural components of biological membranes.
They are amphiphatic molecules in which a glycerol bridge links a pair of hydrophobic chains and an hydrophilic polar headgroup, phosphocholine. ${ }^{31}$ The hydrophobic part consists of two hydrocarbon chains of saturated or unsaturated fatty acids, which esterify the same number of hydroxyl groups of glycerol, and each chain can present $10-28$ carbon atoms. ${ }^{93}$

Amphipathic lipids have the ability to spontaneously form bilayer aggregates when dispersed in an aqueous solution, involving within a certain volume of solvent. These structures may consist of one or several concentric membranes, varying in size from $20 \mathrm{~nm}$ to a few micrometers in diameter, with a membrane thickness approximately equal to $4 \mathrm{~nm} .^{31}$

Phospholipids are abundant in nature and certainly the most used in the preparation of liposomes are those containing choline. ${ }^{33}$ These are called lecithin or phosphatidylcholine (of the "lekithos", a Greek word meaning egg yolk) and are dipolar molecules at physiological $\mathrm{pH}$, with the quaternary ammonium group presenting a positive charge and a negative charge in the phosphate group. ${ }^{94}$

Lecithin from natural sources, as extracted from egg yolk or soybean, is a mixture of several molecules with carbonaceous chains of different lengths and different degrees of saturation. The most abundant fatty acid in lecithin from egg yolk is palmitic acid (35.3\%), followed by oleic acid. ${ }^{31}$ However, lecithin can also be obtained by synthesis, presenting a welldefined composition, particularly with respect to acyl chains, which can be obtained from saturated or unsaturated hydrocarbon chains, with greater or lesser number of carbon atoms, equal or different. This type of phospholipid, such as dipalmitoylphosphatidylcholine (DPPC) or dimyristoylphosphatidylcholine (DMPC), can be easily characterized for various thermodynamic parameters, compared to the heterogeneous populations that are in the natural phospholipids. ${ }^{33}$ Besides phospholipids, the liposomes can also include other molecules, also present in natural membranes, such as cholesterol. $^{95}$ Cholesterol improves the fluidity of the membrane bilayer, reduces the permeability of water-soluble molecules through the membrane, and improves the stability of the bilayer membrane in the presence of biological fluids, such as blood/plasma. ${ }^{96}$

One of the main physical characteristics of lipid bilayers is the existence of a temperature where the organization of phospholipids changes. Thus, for different values of temperature, lipid bilayers can present itself in two distinct thermodynamically phases, occurring transition from one phase to another by varying the temperature. ${ }^{31}$ Therefore, the lipid bilayers can be presented in a phase of great order, designated by solid-gel state, and for higher temperatures, a more fluid phase called liquid crystal, ${ }^{31,33}$ as shown schematically in Figure 4.

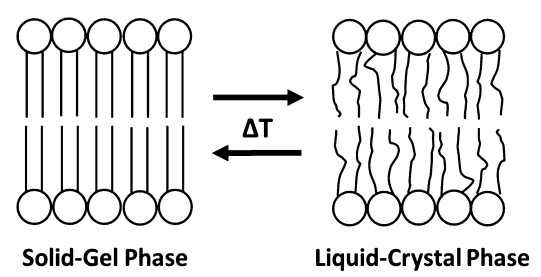

Figure 4. Schematic representation of the organizational structure presented by the hydrocarbon chains of phospholipids in the gel-solid state and liquid crystal. $\Delta T$ corresponds to the variation of temperature. 
The temperature of transition from one stage to another is called temperature of phase transition $\left(T_{\mathrm{c}}\right)$ and is specific to a particular lipid. Thus, when the temperature of the system is lower than $T_{c}$ of the phospholipid components of a given bilayer, this presents an ordered structure where the hydrocarbon chains are in an extended conformation and tight packaged, and the freedom of movement is severely restricted. Above $T_{\mathcal{O}}$ increases the mobility of the acyclic chains in the membrane, the area occupied by each phospholipid molecule is higher and the bilayer thickness decreases. ${ }^{31,33}$

The influence of hydrocarbon chain length and unsaturation (as well as headgroup) on the value of $T_{c}$ for a membrane composed of different phospholipids is considerable. In general, increasing the chain length or the saturation of the chains increases the transition temperature. For a homogeneous composition of membranes is possible to state a value of the phase transition temperature. However, for mixtures of phospholipids, $T_{\mathrm{c}}$ comprises a range of temperatures. The width of this interval depends strongly on the lipid composition and can cover more than $10{ }^{\circ} \mathrm{C}$ or even be absent in certain mixtures of lipids, for example, in the presence of high concentrations of cholesterol (50\%). The $T_{c}$ described for DMPC is $23.5{ }^{\circ} \mathrm{C}$ and for DPPC is $41.4{ }^{\circ} \mathrm{C}$, while the egg yolk phosphatidylcholine (EPC), an heterogeneous mixture, has a transition temperature of -15 to $-7{ }^{\circ} \mathrm{C}$. . $^{31,33}$

An understanding of phase transitions and fluidity of phospholipids membranes is important both in the manufacture and exploitation of liposomes, since the phase behavior of a liposome membrane determines such properties as permeability, fusion, aggregation, and protein biding, all of which can markedly affect the stability of liposomes and their behavior in biological systems. ${ }^{31,97}$

Another important feature inherent to the membrane structure is its permeability, which is highly dependent on the dynamics and thermodynamics of membrane phase. ${ }^{33}$ The degree of diffusion of molecules and ions through the bilayer varies considerably. The bilayers are sufficiently permeable to hydrophobic molecules but may constitute a barrier to hydrophilic molecules. Thus, compounds that are more hydrophilic can pass through the membrane, but more slowly, or else through typical channels in the membrane. The water and ions such as calcium ions, potassium, sodium, and chlorine, for example, pass through the membrane channels (proteins), which control the entry and exit of these compounds in the cell. ${ }^{31}$

3.2. Classification of Liposomes. Apart from their chemical constituents, liposomes can be characterized based on their number of lipid bilayers (lamellae) and size. Thus, without any further processing, the dispersion of phospholipids in water leads to a polydisperse population known as multilamellar vesicles (MLVs), whose sizes are usually ranging from 0.4 and $3.5 \mu \mathrm{m}$ of diameter. ${ }^{31}$ Each vesicle consists of multiple lipid bilayers (around five or more) concentrically arranged, between which there is a fraction of internal aqueous medium. The MLVs were used in early studies being the vesicles with the most immediate preparation. The liposomes formed by a single bilayer are called large unilamellar vesicles (LUVs) if its size exceeds $50 \mathrm{~nm}$, according to some authors, ${ }^{93}$ or $100 \mathrm{~nm}$, according to others. ${ }^{96}$ The small unilamellar vesicles (SUVs) are characterized by approximate diameters from 25 to $50 \mathrm{~nm}$ and unilamellar vesicles of intermediate size (intermediate sized unilamellar vesicles (IUVs)) for intermediate sizes. ${ }^{31}$ In addition to these unilamellar vesicles, it should be also considered the giant unilamellar vesicles (GUVs), larger than $1 \mu \mathrm{m}$ and can reach the tens of micrometers size, comparable to size of a eukaryotic cell $\left(10-100 \mu \mathrm{m}\right.$ in diameter $\left.^{31}\right)$. Figure 5 represents the types of liposomes described.

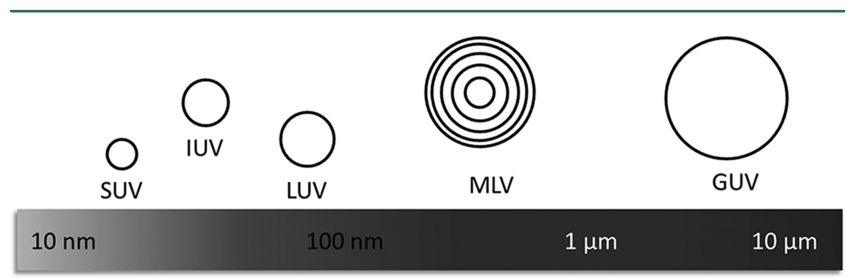

Figure 5. Schematic representation of the different types of liposomes classified according to the size and number of lipid bilayers. Each line represents a lipid bilayer.

According to the aim of study, it should be selected the more suitable type of liposomes, usually MLVs, LUVs, or SUVs. For example, in the study of structural, dynamic, and thermodynamic properties of membranes, in which the sensitivity can often be a problem, normally it is preferred the MLVs, due to its higher lipid concentration. Contrariwise, unilamellar structures are chosen, particularly the LUVs, in studies of membrane permeability and the roles of proteins. SUVs, due to the high curvature, present anomalies in the packaging of lipids that make them susceptible to degradation in the presence of biological molecules. ${ }^{98}$ Additionally, LUVs have a volume fraction for encapsulation much larger than SUVs for the same lipid concentration. ${ }^{5}$

When they are applied as vehicles, multilamellar structures are usually preferred in the case of hydrophobic molecules to be encapsulated, while LUVs are more appropriate for the hydrophilic molecules, since they have a large volume/surface. Conversely, the MLVs provide a more sustained drug release than LUVs, as their membranes are being gradually degraded at the site of action. ${ }^{31,33}$ However, if it is desirable rapid delivery of the drugs, the LUVs are the most suitable ones. ${ }^{99}$ For the surface studies there is a need of large surface/volume ratio, and the obviously preferred choice are SUVs, while GUVs are too fragile for most applications. Although, these vesicles are very useful for studies of basic features, such as elasticity, permeability, and tensile strength of bilayers, in which the optical microscope is the main method used. ${ }^{5}$

3.3. Preparation of Liposomes. The widespread use of liposomes for various purposes has created the need to develop preparation methods, which should be efficient, reproducible, and with the greatest simplicity. The methods of preparation of liposomes, currently available, are diverse and may have numerous variants. The classic preparation of liposomes, initiated by Alec Bangham in 1965, and used nowadays, is entitled by the thin film hydration method. ${ }^{100}$ This preparation process may undergo some changes, particularly regarding the organic solvent used and the possible addition of glass beads, from the drying of lipid and parameters agitation, such as time, intensity, mode of agitation, and temperature. ${ }^{33}$ However, this method always leads to the formation of MLVs, which are very heterogeneous regarding size, shape, and number of lipid bilayers, and a small percentage of LUVs and SUVs. ${ }^{101}$ Therefore, it is necessary to submit MLVs to further processes, when vesicles with specific sizes are needed. These processes include mechanical, chemical, or electrostatic methods that allow obtaining unilamellar liposomes. There are also methods 
that use already preformed vesicles, SUVs to form mainly LUVs, small MLVs, and GUVs. These methods are based primarily on melting, freezing, and thawing or dehydration/ rehydration of liposomes. However, the most frequently used methods are mechanical, and the most widespread of these are the sonication and extrusion, although the homogenization and French press can also be applied. ${ }^{28,31,33}$

The major advantages of the extrusion technique are directly related with a possibility to make homogeneous populations of LUVs in the size range of $40-150 \mathrm{~nm}$. Nevertheless, a drawback associated with this type of equipment is the inconvenience experienced with the clog of pores in the membrane particularly when processing concentrated suspensions and/or the liposomes sizes are substantially greater than the membrane pores sizes. ${ }^{102}$

Sonication is also one of the most popular methods to prepare liposomes from the aqueous dispersion of phospholipids, which has been used from the beginning of the study of liposomes. ${ }^{28}$ Since that several studies have been performed with ultrasound in order to obtain unilamellar vesicles with defined sizes.

Finer and co-workers ${ }^{29}$ found that the collisions produced by ultrasound led to complete disruption of the multilamellar particles, with the formation of short-lived bilayer fragments or other forms of small lecithin aggregates. These fragments then reaggregate to form single-shelled vesicles of roughly uniform size.

Woodbury and co-workers performed a study where the main goal was to obtain a detailed characterization of the various lipid suspensions produced by using different sonication times. ${ }^{35}$ They had shown that mildly sonicated liposomes generally have a bimodal distribution and are not well described by single mean.

The studies of treatment time of ultrasound have been also performed by Maulucci et al. ${ }^{34}$ The results indicate that the lipid film, upon sonication, forms LUVs, which then progressively reduce their size when increasing the sonication time. At shorter sonication time, the total energy transferred by sonication was not sufficient to reduce MLVs, and if the treatment is too long, the vesicles are damaged by the generated free radicals. Therefore, an optimal sonication time must be determined for the specific use of the vesicles.

The size changes of liposomes, as well as the polydispersity and lamellarity of the systems as a function of the ultrasound power applied, were also studied. ${ }^{36}$ They concluded that the increase of ultrasound power decreases the number of lamellae, the vesicle size, and the polydispersity, obtaining an homogeneous distribution of lipid vesicles.

Later, the effect of sonication and freezing-thawing on the aggregate size and dynamic surface tension of aqueous DPPC dispersions was studied. ${ }^{37}$ When DPPC dispersions were prepared using extensive sonication, they form vesicles that were quite clear, transparent, and stable for at least 30 days. The average dispersed vesicles diameter was $80 \mathrm{~nm}$ in water and $90 \mathrm{~nm}$ in standard phosphate saline buffer. After a freezethaw cycle, this dispersion became turbid, and precipitates of coagulated vesicles were observed with large particles of average size of $1.5 \times 10^{3} \mathrm{~nm}$. The vesicle coagulation is due to the local salt concentration increase during the freezing of water. This dispersion had shown much higher equilibrium and dynamic surface tension than those before freezing. When this freezethawed dispersion was subjected to a resonication at $55{ }^{\circ} \mathrm{C}$, smaller vesicles with sizes of $70 \mathrm{~nm}$ were produced and a lower surface tension behavior was restored as before freezing. ${ }^{37}$

Recently, Richardson and co-workers ${ }^{38}$ explore also the role of cavitation, using a bath sonicator, in manipulating liposome size. They hypothesize that ultrasonic cavitation phenomena play a key role in altering the size distribution of liposomes processed in an ultrasonic bath. They manipulate the size of liposomes by correlating changes in liposome size with cavitation emissions at various acoustic intensities and static pressures. The authors developed a mathematical model based on the Rayleigh-Plesset equation of bubble dynamics and principles of acoustic microstreaming to estimate the shear field magnitude around an oscillating bubble. This model predicts the ultrasound intensities and pressures needed to create shear fields sufficient to cause liposome size change. The results of mathematical models show that stable (noncollapse) cavitation can generate sufficient shear through acoustic microstreaming to reduce liposome size. Moreover, these mathematical models of acoustic microstreaming can qualitatively explain the effects of pressure and acoustic intensity on liposome size reduction. Richardson and co-workers proved that the microstreaming around oscillating bubbles, and not necessarily collapse cavitation events, create shear sufficient to reduce the size of the liposomes during ultrasonic processing.

Besides various powers, it was also study the influence of different ranges of frequencies $(43-480 \mathrm{kHz})$ to obtain liposomes prepared with $\mathrm{L}-\alpha$-dilauroylphosphatidylcholine. It was observed a faster reduction of the mean size of liposome when a lower frequency was used. ${ }^{39}$ The effect of frequency on the size reduction of liposome can be related to the strength of cavitation caused by the difference in the bubble dynamics. The amplitude of the oscillation of a cavitation bubble is larger at lower frequency because the bubble experiences longer time of negative pressure to glow larger. ${ }^{103}$ The impulsive shock wave and the microjet stream created by a bubble are thus stronger at the lower frequency, and consequently a size reduction of liposome was faster.

More recent studies performed by Silva et al. ${ }^{40,41}$ reported the importance of the different parameters of sonication, such as power delivery, time, and distance from ultrasound tip to base of reactor, when a transducer of $20 \mathrm{kHz}$ is used to obtain LUVs. The data obtained reveal the importance of LUVs preparation in the nodal (lower production of ${ }^{\circ} \mathrm{OH}$ ) and antinodal (higher production of ${ }^{\circ} \mathrm{OH}$ ) horn position of ultrasound sources.

Another approach based on the parameters previously mentioned ${ }^{40,41}$ was used to obtain the reduction of liposome sizes prepared with internal wool lipids (IWLs). ${ }^{42}$

3.4. Stability of Liposomes. Over time, the liposomes can undergo several types of changes, including physical and chemical modifications. ${ }^{90}$ However, if prepared and stored under very specific conditions, the occurrence of these changes can be minimized. A stability study program must include the product characterization.

Average size distribution of liposomes determined at the time of their preparation can change upon their storage. Independently of the preparation method, liposomes tend to fuse and grow into bigger vesicles, which is a thermodynamically more favorable state. Since this phenomenon may occur mainly at the $T_{\mathrm{c}}$, it is advisible to store the suspensions of liposomes at a temperature different from that. Additionally, it can be advantageous to include a sufficient proportion of cholesterol into the membrane to reduce or eliminate the phase 
transition, particularly if it occurs in a temperature range near which the liposomes are stored or handled. The macroscopic aspect, average size, and size distribution are important parameters to evaluate and can be obtained by examination of the suspension or by using the photon correlation spectroscopy (PCS) and/or electron microscopy. ${ }^{31,33,41,96}$

Chemically, phospholipids are susceptible to oxidation and hydrolysis reactions, which can be accelerated by the free radicals formed in the cavitation bubbles during the preparation of the sonicated phospholipid suspension. ${ }^{32}$ Although, according to Kruus et al., ${ }^{104}$ the formation of free radicals is not a major problem when low frequencies $(\approx 20 \mathrm{kHz})$ and short sonication times $(\approx 20 \mathrm{~min})$ are used. Rabinovich-Guilatt et al. ${ }^{105}$ proved that the use of a temperature of $50{ }^{\circ} \mathrm{C}$ over $24 \mathrm{~h}$ induces only $1.6 \%$ of phosphocholine hydrolysis.

Although, the most susceptible to degradation are lipids containing double bonds, since the unsaturation permits delocalization of the remaining unpaired electron along the lipid chain and lowers the energy of this state (and hence increases the probability of it being formed). The polyunsaturated fats are thus particularly susceptible to oxidative degradation. $^{31,33}$ The oxidative degradation of the lipids in general can be minimized by protecting the lipid preparations from light, by adding antioxidants, or by producing the product under nitrogen or argon environment. ${ }^{33,96,106,107}$ The hydrolysis of phospholipids leads to the formation of lysophospholipids and free fatty acids. ${ }^{108-110}$ The presence of lysophospholipids enhances the permeability of liposomes, and thus it is essential to keep its level to a minimum in a given preparation. ${ }^{110}$ Hydrolysis is strongly affected by temperature and $\mathrm{pH}$. In fact, this degenerative chemical process can occur to a lesser extent at low temperatures and $\mathrm{pH}$ values close to neutrality. ${ }^{31}$ On the other hand, the use of lipids that contain ether linkages instead of ester, such as those found in the membranes of halophilic bacteria, completely avoids the hydrolysis reactions. ${ }^{31,111,112}$

Other factors to be taken into consideration prior to starting a stability study are the formulation factors and environmental conditions, which may influence the stability of liposomes. Influences of formulation factors such as $\mathrm{pH}$, buffer species, ionic strength, and solvent system play a major role in stabilizing a liposome formulation. ${ }^{96}$

3.5. Liposomes as Delivery Systems. The ability of liposomes to dissolve, protect, and drive water or fat soluble drugs as well as its biocompatibility with cell membranes and the possibility of adding certain ligands to their surface achieving a particular cell type were the main reasons for their implementation systems as carriers of drugs in cosmetic, pharmacology, and medicine..$^{33,92,113,114}$ One of the main advantages of using liposomes as carriers is the easy drug incorporation, independently of their charge or molecular weight, and the accommodation of substances with very different polarity characteristics on the same system ${ }^{114,115}$ (Figure 6).

As a pharmaceutical formulation, the main advantages conferred by liposome encapsulation of drugs are increased solubility of lipid soluble drugs and the protection granted by these systems to hydrolysis of the drugs, caused for example by the action of degenerative enzymes, adverse $\mathrm{pH}$, and action of light. $^{33}$

The application of liposomes in vivo is limited by its retention at the level of the reticuloendothelial system (RES). Generally, liposomes sizes for use in parenteral administration are between

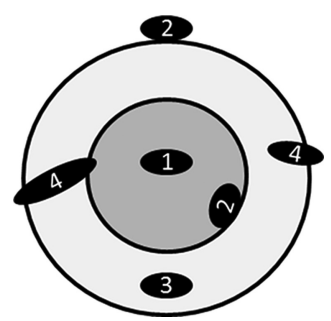

Figure 6. Possible locations of water-soluble drugs or other compounds without (1) or with (2) electrostatic or ionic bonds and lipophilic (3) or amphipathic (4) drugs in the phospholipid membrane.

about 0.1 and $0.3 \mu \mathrm{m} .{ }^{116}$ In fact, liposomes in the bloodstream are quickly captured by the macrophages as well as the liver, spleen, lymph nodes, lungs, and bone marrow, which have the function of processing the foreign agents that enter in the body. ${ }^{117}$ Thus, the half-life in plasma of liposomes can be reduced to few minutes. The problems led to the development of liposomes, with the inclusion of certain molecules in their outer layer, with new transport options in order to prevent their elimination by the RES. Indeed, the physical characteristics and composition of liposomes affects their capture by the RES, such as the size and fluidity. Therefore, larger liposomes are captured more quickly as well as the more rigid liposomes due to its constitution. ${ }^{118}$ One way to going through this problem is coating liposomal vesicles with a hydrophilic polymer, such as poly(ethylene glycol) (PEG), which reduces uptake by the RES. ${ }^{119-121}$ As a result, coated liposomes remain in circulation longer than conventional liposomes. Additionally, incorporating targeting ligands on the surface of the liposomes, it is possible to direct them to certain organs. For example, an association with folic acid or antibodies, which are specific to particular cell. $^{117,122-126}$ The modified liposomes are generically called stealth liposomes and may increase 100 times the half-life. ${ }^{121,127}$

\section{POLYMERIC PARTICLES}

It has recently become a trend to develop new and suitable biomaterials, due to their bioavailability, biocompatibility, and biodegradability coupled with low toxicity being the usefulness of polymers in drug delivery systems (DDS) well established. Continued improvement and accelerating research and development in polymeric materials have played a vital role in the progress of most controlled-release technologies. In the past 25 years, there has been a considerable increase interest in this technology, as is shown by the increasing number of publications and patents in the area of controlled drug-release systems using synthetic as well as naturally occurring polymeric materials. $^{128}$

The furthermost nano- and microparticle formulations are effectively based on nano- and micrometric-scaled emulsions. Therefore, the study of particle formulation has to include the knowledge of emulsion formation phenomena. Nano- and microemulsion generation is very commonly performed with such high-energy emulsification methods, particularly exploited in polymeric materials. ${ }^{129,130}$ The formation of such nano- and micrometric scaled particles is governed by directly controllable formulation parameters, such as the quantity of energy and nature of the components.

In the area of engineered nano- and microparticles of polymer origin there is a vast area of possibilities for the chemical composition. They can be divided into two broad 
classes: protein-based and non-protein-based nano- and microparticles platforms. Non-protein-based templates include PEG, poly(amidoamine) (PAMAM), dextran, chitosan, etc. ${ }^{131}$

4.1. Protein-Based Nano- and Microparticles. Among of polymers systems, those based on proteins are very promising ones. Proteins are a class of natural molecules that have unique functionalities and potential applications in both biological and material fields. ${ }^{132}$ Nano- and microstructures derived from proteins, especially protein particles, are biodegradable, nonantigenic, metabolizable, and can also be easily amenable for surface modification and covalent attachment of drugs and ligands. ${ }^{133,134}$

To develop protein-based templates, there are several criteria to be followed: first, the novel matrix should be easy to obtain with relatively low cost; second, the new template has to maintain the cells' viability and not cause any immunogenic reactions; third, the protein-based platform should be stable and keep its chemical and mechanical properties once it has been delivered in vitro or in vivo; fourth, the drug molecules should also be stable in this new material; and fifth, the biodegradable rate of this new novel platform should be slower than that of the drug molecule release rate. ${ }^{135}$

A variety of proteins have been used and characterized for drug delivery, such as albumin, ${ }^{136-138}$ silk fibroin (SF), ${ }^{139,140}$ casein, ${ }^{141,142}$ collagen, ${ }^{143,144}$ and gelatin. ${ }^{145-147}$

The serum albumin protein has been one of the most extensively studied and applied in the preparation of nano- and microparticles because of its availability, relative low cost, stability, and unusual ligand-binding properties. For this reason, its main characteristics will be pointed out in this review.

Albumin is a globular protein, which is emerging as a versatile protein carrier for drug targeting and for improving the pharmacokinetic profile of bioactive compounds. This is the most abundant plasma protein (35-50 $\mathrm{g} \mathrm{L}^{-1}$ human serum) with a molecular weight of $66.5 \mathrm{kDa} .{ }^{148}$ Like most of the plasma proteins, albumin is synthesized in the liver and is responsible for the transport of fatty acids and others lipids that would otherwise be insoluble in the circulating plasma. ${ }^{149}$ The three-dimensional (3-D) structure of human serum albumin (HSA) has been elucidated by X-ray structure analysis. ${ }^{150,151}$ The approximate 3-D shape of HSA can be described as an ellipsoid consisting of three flexible spheres in a row (domains I, II, and III) and is illustrated schematically in Figure 7.

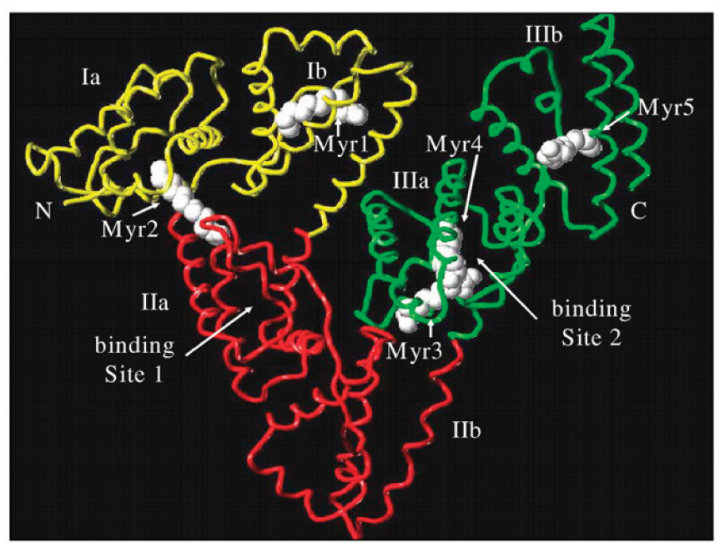

Figure 7. X-ray structure of HSA. Reproduced with permission from ref 151. Copyright 1994 Elsevier.
HSA is one of the smallest proteins present in blood plasma. Both size and abundance explain the fact that so many metabolic compounds and therapeutic drugs are transported by this protein. The binding sites for metabolic substrates and diagnostic as well as therapeutic drugs have been extensively studied and reviewed. ${ }^{152,153}$ These properties as well as its preferential uptake in tumor and inflamed tissue, its ready availability, its biodegradability, and its lack of toxicity and immunogenicity make it an excellent candidate for drug delivery. ${ }^{152}$

The bovine serum albumin (BSA) is also a very used protein in the preparation of microparticles due to the lower cost when compared with the HSA. The primary structures of HSA and BSA are homologous by $80 \% .{ }^{154}$ Albumins are characterized by a low content of tryptophan, glycine, and methionine and a high content of cysteine ( 17 disulfide bonds and one sulfhydryl group) and the charged amino acids (a.a.), aspartic and glutamic acids, lysine, and arginine. The difference between the two proteins is that, in HSA, some hydrophobic a.a. are replaced by other hydrophobic residues, e.g., BSA holds two tryptophan's a.a. in its structure and HSA has only one. ${ }^{149,154}$

4.2. Preparation of Protein-Based Nano- and Microparticles. In the later of 1960 s, Rhodes and co-workers were the first investigators to produce microspheres from natural macromolecules for medical applications. ${ }^{155}$ By slightly modifying the method proposed by Zolle, ${ }^{156}$ they succeed in producing HSA particles with a size bellow one micrometer. ${ }^{156}$ The particles were formed by heat denaturation of a water-inoil emulsion of albumin. However, the heat denaturation can be harmful for the entrapped drugs or bioactive molecules. To solve this problem, the heat denaturation was replaced by the chemical cross-linking agents, such as glutaraldehyde. Nevertheless, this method yields microspheres with a short storage life, low stability, and high toxicity. These issues motivate new methods of microparticle manufacture in order to improve protein stability, allow the further sterilization, and eliminate the addition of cross-linking agents.

Two main groups of devices are used in the literature: the rotor/stator devices, which appear in the first articles of nanoand microparticles, and high-efficiency devices, including highpressure homogenizers and ultrasound generators. ${ }^{157}$ In general, high-energy nano- or microemulsification methods produced by homogenizer or ultrasound are widely employed for polymeric nano- and microparticle generation. Comparing the both techniques, it is possible to state that the limitations of high-pressure homogenizers are related with the processed fluid, which has the potential to pick up metal and oil contaminants from the homogenizer pump and be further contaminated by the pumps seals.

Suslick and co-workers pioneered sonochemical synthesis of protein microspheres, where simple sonication of a protein solution produces microcapsules filled with air or a nonaqueous liquid. $^{45}$ They were made of BSA and were filled with $n$ dodecane, $n$-decane, $n$-hexane, cyclohexane, or toluene. The synthesis was conducted under high-intensity ultrasonic probe upon sonicating the precursor solution under air or $\mathrm{O}_{2}$. The average diameter of the protein microspheres was $2.5 \mu \mathrm{m}$ with a narrow size distribution. Ultrasonic irradiation of HSA generates similar microspheres to those of the BSA, and the same was obtained for the protein microspheres of hemoglobin (Hb). ${ }^{49}$

In-depth mechanistic studies revealed that mechanism of proteinaceous microspheres preparation is a direct result of the 
chemical effects of ultrasound irradiation on an aqueous medium. Indeed, the microspheres formation is a combination of two acoustic phenomena: emulsification and cavitation. Ultrasonic emulsification is a well-known process and does occur in this biphasic system being this phenomenon necessary for microspheres formation. Nevertheless, in vortex mixing, emulsification occurs but microspheres are not formed. Consequently, emulsification by itself is not sufficient for microspheres formation. Ultrasonic emulsification creates the microscopic dispersion of the protein solution necessary to form the shape of the proteinaceous microsphere shell. However, ultrasonic irradiation of liquids produces acoustic cavitation: the formation, growth, and implosive collapse of bubbles creating transient hot spots with enormous peak temperatures and production of free radicals. Aqueous sonochemistry caused by the implosive collapse of bubbles produces ${ }^{\circ} \mathrm{OH}$ and $\mathrm{H}^{\bullet}$ radicals and, in the presence of $\mathrm{O}_{2}$, superoxide $\left(\mathrm{O}_{2}{ }^{--}\right)$and $\mathrm{HO}_{2}{ }^{\bullet}$ radicals. ${ }^{\circ} \mathrm{OH}, \mathrm{O}_{2}{ }^{-}$, and $\mathrm{HO}_{2}{ }^{\bullet}$ radicals are all potential protein cross-linking agents. Using various trapping agents, they concluded that the important oxidant involved in microsphere formation is superoxide. ${ }^{47,48}$ They proposed that the cysteine, which is present in BSA, HSA, and $\mathrm{Hb}$, is oxidized by the $\mathrm{O}_{2}{ }^{--}$. The microspheres are then held together by protein cross-linking through disulfide bounds from cysteine oxidation.

In a later publication, Suslick and Grinstaff reported on the preparation of aqueous suspensions of air-filled proteinaceous microbubbles. ${ }^{46}$ The synthesis involves the ultrasonic irradiation of aqueous protein solutions in the presence of $\mathrm{O}_{2}$. Yields and size distribution of HSA and BSA microbubbles were determined as a function of various experimental parameters. The ultrasound irradiation was conducted for $3 \mathrm{~min} .{ }^{46}$ This irradiation time is typical for the optimal formation of the protein microspheres. It is worth mentioning that the difference in the formation of the liquid- and air-filled bubbles is in the position of the sonicator. In a typical synthesis of liquid-filled protein microspheres, the organic liquid is layered over a $5 \% \mathrm{w} /$ $\mathrm{v}$ protein solution and the horn is positioned at the water/ organic interface. For air-filled microbubbles, the horn is placed at the water/air interface.

Another approach has been developed about the mechanism of microspheres formation with ultrasound systems. ${ }^{52}$ To probe whether the sonochemical microsphere formation process is more general and can be applied to proteins that do not contain cysteine residues, an attempt was made employing this method to streptavidin, which has no sulfur residues. ${ }^{32}$ They had extended the sonochemical method to this non-sulfurcontaining protein and demonstrated the formation of protein microspheres. Nevertheless, no microspheres were obtained when the $\mathrm{pH}$ was kept at 7 . However, when the $\mathrm{pH}$ was lowered to 6.0, by adding a concentrated acidic solution, microspheres were formed. According to the proposed explanation, hydrophobic or thermal denaturation of the protein after the initial ultrasonic emulsification assists in microsphere formation. A contribution is provided by the lowering of the $\mathrm{pH}$, which helps to neutralize the basic $\mathrm{COO}^{-}$ edges, thus creating a more favorable hydrophobic environment. To verify whether this hypothesis is correct, a poly(glutamic acid) protein was sonicated. ${ }^{52}$ This protein carries only carboxyl groups on the side chain. Microspheres of the poly(glutamic acid) were formed only at a $\mathrm{pH}$ lower than 4.5. Thus, the authors concluded that hydrophobic interactions, which become more dominant in an acidic medium, are responsible for the production of the microspheres in a poly (glutamic acid) as well as in streptavidin.

In addition, sodium polyglutamate (SPG) microspheres have also been reported that are stabilized by hydrogen-bonding networks instead of covalent cross-linking. ${ }^{56}$ More specifically, the dominant interaction between the polymer chains are a network of hydrogen bonds or ion pairs: $\left[\mathrm{RCO}_{2}^{-} \cdots \mathrm{M}^{+} \cdots \mathrm{O}_{2} \mathrm{CR}\right]$ in which $\mathrm{M}^{+}=\mathrm{H}^{+}$or $\mathrm{Na}^{+}{ }^{56}$

Gedanken and co-workers ${ }^{62}$ have synthesized microspheres made of a few different proteins. The three proteins used were BSA, green fluorescent protein (GFP), and cyan fluorescent protein-glucose binding protein-yellow fluorescent fused protein (CFP-GBP-YFP). The two synthesized microspheres made of mixed proteins are BSA-GFP and BSA-(CFP-GBPYFP). The authors characterized the three possible arrangements from the assembly of two different kinds of proteins in microsphere structures. First, the two combined proteins form the microspheres walls. Second, the first protein forms the microspheres walls, and the second one is encapsulated inside the liquid-filled proteinaceous microsphere bubble. Third, each kind of protein forms one-protein microspheres. ${ }^{62}$

Recently, Silva et al. ${ }^{66}$ highlighted the insights on the mechanism of protein microspheres formation using two different proteins, namely BSA and SF from Bombyx mori. As was previously referred, BSA is a globular protein. In contrast, $\mathrm{SF}$ is a fibrous protein and is mainly composed of hydrophobic a.a. without cysteine residues in its structure. The SF from Bombyx mori is an insoluble protein, and its primary structure has been determined to be composed dominantly of a six a.a. residue motif, i.e., -Gly-Ala-Gly-Ala-Gly-Ser- (Figure 8). ${ }^{158-160}$

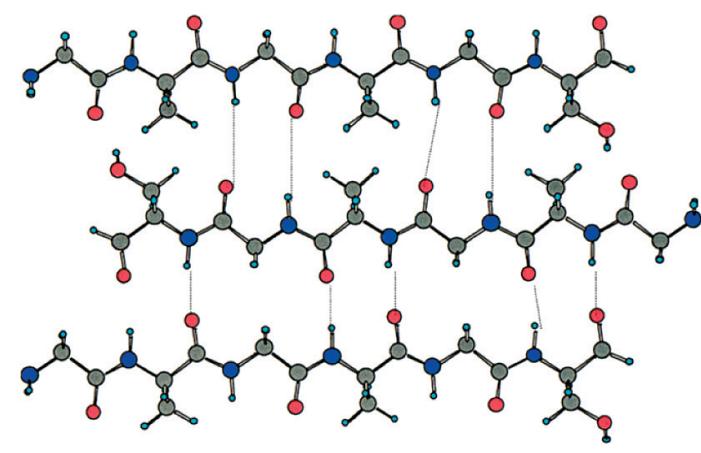

Figure 8. Three-chain layer of a polypeptide GAGAGS model. Reproduced with permission from ref 161. Copyright 2001 American Chemical Society.

The authors report the influence of different ratios of aqueous/organic phase and protein concentration on microspheres production using BSA and SF. An increase on protein concentration promotes $\approx 100 \%$ of yield on particles formation, independently of aqueous/organic ratio used. It was proved that the use of lower organic fraction leads to smaller sizes particles. It was also found that these parameters demonstrate to be an important tool to control the sizes of particles, ranging from 300 to $1500 \mathrm{~nm}$. The conformation assessment obtained with Fourier transform infrared (FT-IR) analysis demonstrated a change on the secondary structure of SF upon sonication treatment, presenting an increase on the amount of $\beta$-sheet. Conversely, the sonochemical treatment did not affect the secondary structure of the globular protein, BSA.

Based on these different sonochemical approaches to synthesize protein microspheres, a multitude of parameters 
should be controlled as well as the physicochemical protein characteristics to determine the main mechanism of protein microspheres formation for each protein in particular.

Cavaco-Paulo and co-workers ${ }^{67}$ further extended the sonochemical method to new engineering peptides, with a range of sizes and sequences, to highlight the mechanism of proteinaceous microspheres formation. It was reported the importance of some a.a. residues and their arrangement in peptide construction in respect to obtain microspheres with adjustable properties to cover a wide range of applications. The authors proved that the larger peptides with separated and clear hydrophobic and hydrophilic areas lead to small and more stable spheres.

4.3. Biological Activity of Protein-Based Nano- and Microparticles. A related effort by Suslick and Wong was the biological activity of microspheres formed with $\mathrm{Hb}^{49}$ The microspheres of $\mathrm{Hb}$ were filled with air and are described as having many of the ideal characteristics needed for use as blood substitute. The results of the oxygen binding have shown that $\mathrm{Hb}$ microspheres can bind and release oxygen at the same oxygen pressures as native $\mathrm{Hb}$. The authors have calculated the oxygen-carrying capacity of the $\mathrm{Hb}$ microbubbles and found that for $\mathrm{O}_{2}$-filled microbubbles it is greater by $50 \%$ than whole blood $\left(0.32 \mathrm{~mL}\right.$ of $\mathrm{O}_{2}$ per $\mathrm{mL}$ of microbubble versus $0.2 \mathrm{~mL}$ of $\mathrm{O}_{2}$ per $\mathrm{mL}$ of blood). ${ }^{49}$

Later, Avivi and Gedanken performed two other investigations probing the biological activity of proteinaceous microspheres. ${ }^{55,57}$ In the first, it was found that unlike a denaturation process, where the biological activity of the protein is destroyed, the sonochemical process leading to the microspherization of a protein reduces its biological activity but does not destroy it. Avidin microspheres are still active after the sonochemical process. Thus, it was verified that avidin microspheres have the ability to bind biotin, but to a lesser degree than the native protein. ${ }^{55}$ In a second study related also to the biological activity of proteinaceous microspheres, Avivi ${ }^{57}$ formed microspheres of $\alpha$-amylase (1,4- $\alpha$-D-glucanohydrolase, endoamylase), a protein known to hydrolyze starch, glycogen, and related polysaccharides by randomly cleaving the internal $\alpha$-1,4-glucosidic linkages. Microspheres of $\alpha$-amylase were compared for their catalytic activity with those of the native protein. They concluded one more time that the sonochemical method does not destroy the enzymatic activity of the microspheres. In this research, it was demonstrated that the sonication leading to the modification into microspheres of two enzymes, $\alpha$-amylase and $\alpha$-chymotrypsin, is not a denaturation process. The protein microspheres are catalytically active, but their reactivity is reduced as compared to the native protein.

More recently, it was developed a new methodology to recover the biological function of protein. ${ }^{68}$ The refolding of ribonuclease A (RNase A) microspheres, assisted by protein disulfide isomerase, is highlighted in this study. The ultrasound application was shown to induce a loss of $35 \%$ of RNase A enzymatic activity when compared to the native RNase A, and protein disulfide isomerase was able to restore it. ${ }^{68}$ Moreover, the application of protein disulfide isomerase on RNase A microspheres emulsion, in the presence of appropriate oxidative environment, suggested the refolding of microspheres into the aqueous medium by a protein disulfide isomerase induced structural change.

4.4. Protein Nano- and Microparticles Stability. When protein nano- and microparticles are used as the DS, their stability becomes a major concern, mainly against aging and aggregation. This issue has been studied for quite a long time, and a variety of factors are known to influence it. These factors include, but are not limited to, particle size distribution, surfactant type and concentration, aqueous solubility of the dispersed phase, temperature, surface tension, and ionic strength. ${ }^{162}$ To investigate the stability of prepared particles, a program of study should be performed to measure in appropriate interval time their physical stability.

The most important parameter affecting the stability of microspheres is their size and its distribution, which can be determined by PCS. If the microspheres are even slightly soluble in the aqueous phase, mass transfer will occur from the smaller microspheres to the larger ones. This phenomenon, Ostwald ripening, was first theorized by Ostwald in $1901 .^{163}$ Ripening usually occurs in solution due to the lack of monodispersity of microspheres. If all microspheres have the same size, ripening does not occur. The protein microspheres prepared by sonication usually have a broad size distribution due to the disruption of acoustic sound. This limitation can be overturned by the addition of a different surfactant.

The surfactant, also called a tensioactive agent, is frequently employed for the dispersion of one phase in another immiscible phase and for the stabilization of obtained emulsion. It reduces the surface tension of continuous phase, avoids the coalescence and agglomeration of drops, and stabilizes the emulsion. A suitable surfactant should be able to give microspheres of a regular size with small size distribution, guaranteeing a more predictable and stable drug release. There are four different types of surfactant classified by the nature of the hydrophilic part of molecule: anionic, cationic, amphoteric, and nonionic.

It is unrealistic to find a single surfactant that properly works for all different processes. Different formulations impose different requirements on stabilizers. ${ }^{164-167}$ Furthermore, differences in the surfaces characteristics of drug would require different properties of stabilizers. ${ }^{168}$

The amount of stabilizer used will also have an effect on the properties of the micro- and nanoparticles. Most importantly, if the concentration of the stabilizer is too low, aggregation of the polymer droplets will occur and little if any particles will be recovered. Alternatively, if too much of the stabilizer is used, the drug incorporation could be reduced due to interaction between the drug and stabilizer. However, when the stabilizer concentration is between the "limits", adjusting the concentration can be a means of controlling particle size. ${ }^{169}$

Recently, it was demonstrated the importance of adding stabilizers to obtain a monodisperse population of proteinaceous microspheres by sonochemical synthesis. ${ }^{70}$ Several stabilizers were studied, and the poly(vinyl alcohol) (PVA) was shown to be the best choice to obtain BSA and HSA microspheres with small size, homogeneous dispersion, and high stability. The authors also proved that the presence of PVA increased the entrapment efficiency of an antiinflammatory drug, piroxicam.

4.5. Protein-Based Nano- and Microparticles as Delivery Systems. Another important issue is the possibility of using such devices as DDS for different diseases. Since the first reports on the preparation of uniformly sized albumin microspheres in the early 1970s, these biodegradable, biocompatible particles have found various applications. Initially conceived as a diagnostic tool, ${ }^{170}$ albumin particles have been utilized as drug-carrier systems. ${ }^{171}$

In general, the polymeric DS release bioactive agents by the following mechanisms: ${ }^{172,173}$ diffusion, chemical reaction, or 
solvent activation. The release of a bioactive agent from a particle is primarily controlled by diffusion of the bioactive agent through the polymer. ${ }^{174}$ For biodegradable polymers, degradation is a chemical process, whereas erosion is a physical phenomenon dependent on dissolution and diffusion process. As soon as the bioactive agent-containing polymer (A) comes into contact with the external liquid environment, it enters the polymer matrix (B), resulting in a swelling process, which allows the diffusion of the bioactive agent into the external environment ${ }^{174}(\mathrm{C})$, as illustrated in Scheme 1.

Scheme 1. Schematic of the Release of Entrapped Drug or Bioactive Agents from Biodegradable Polymeric Particles ${ }^{a}$

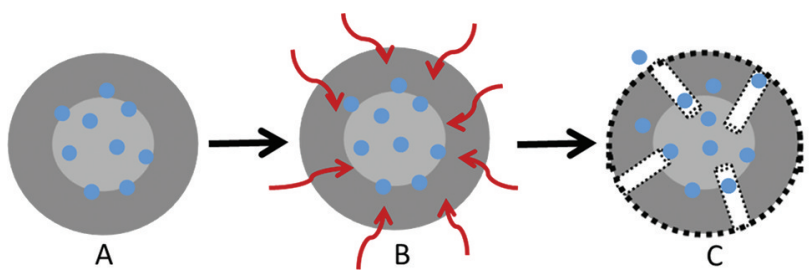

${ }^{a}$ When the polymer device incorporating the bioactive agent $(\mathrm{A})$ is inserted into the environment, the fluid from the surrounding medium enters the particle (B), causing swelling of the device. The fluid creates diffusion channels (C), and the incorporated active agent is released to the external environment. The degradation of material device occurs over time or by chemical reactions (e.g., enzymatic attack and chemical reactions on particular polymeric sites).

Factors influencing the release rate include the molecular size of the bioactive agent and the entrapped percentage into the nano- and microparticle as well as polymer composition and the dimensions and shape of the particles. ${ }^{172}$

Regarding the release profile, strategies to control or render it more adequate for a particular application by means of modifying parameters, such as the surface (by coating, chemical modification, and use of surfactants), or creating dual-release systems (layers of materials that can incorporate different molecules) can greatly improve the properties of several materials. With this, the obtained microspheres can be changed to increase their stability as well as to target an organ or a tissue.

The availability of numerous exploitable side groups in proteins, such as amine, hydroxyl, thiol, and carboxyl groups, makes it possible to use conjugation routes on prefabricated particles.

The encapsulation of the antibiotic tetracycline (TTCL) in BSA microspheres by the sonochemical method was successfully obtained by Avivi and Gedanken. ${ }^{54}$ The amount of TTCL entrapped in microspheres was determined, and the maximum TTCL entrapment capacity was found to be $65 \%$. They concluded that the percentage of the entrapped drug in the BSA microspheres increased with the increase in the concentration of the TTCL in the original solution. Furthermore, the antimicrobial activity of the TTCL into BSA microspheres was tested on two bacterial strains that are sensitive to TTCL, demonstrating an inhibition zone around both bacteria of $30 \mathrm{~mm}$. However, they also concluded that the TTCL trapped within the microsphere and released to the medium is equally active as the TTCL freed from the microspheres by heating. Both sonochemically treated TTCLs are active as antimicrobial agents to the same degree as TTCL that was not sonochemically treated. In the same research group the proteinaceous microspheres of BSA containing an anticancer drug (Taxol) were produced and characterized, and the maximum entrapment capacity of Taxol was found to be above $90 \% .{ }^{175}$ The anticancer activity of the BSA microspheres containing Taxol was also tested. The Taxol encapsulated in the BSA microspheres and organic solvent were released from the microspheres after $24 \mathrm{~h}$ of incubation at the desired locality of the cancer cells. They found that influence of the Taxol microspheres on the cancer cells was different from original Taxol-the increase in the apoptotic cells was greater than the increase in the G2-M phase of the cell cycle. The reason for the behavior of the Taxol-loaded microspheres is related to the organic solvent (mesytilene) that caused the death of some of the cancer cells. Later, the gemcitabine, which is also an anticancer drug, was encapsulated on BSA microspheres (BSA-Gemzar). ${ }^{61}$ The maximum entrapment capacity of Gemzar was found to be above 30\%. The BSA-Gemzar composite was examined for its anticancer activity (in vitro) in renal cancer cells (RCC, 786-O cells) using $[3 \mathrm{H}]$ thymidine incorporation assays. The authors noted that the influence of the Gemzar-loaded microspheres on the cancer cells was significantly greater than that of an equimolar concentration of Gemzar. They also believed that the rapid release of the drug at the target site may be due to the proteases present at the target environment. However, the precise mechanism for the release of drugs at the targeted environment was not clarified by the authors.

Recently, the benefits of encapsulated oil were verified by Silva et al. ${ }^{69}$ The authors reported a novel approach using proteinaceous microspheres of BSA, HSA, and SF containing different organic solvents, namely $n$-dodecane, mineral oil, and vegetable oil, to reduce the activity of human neutrophil elastase (HNE) found in high levels on chronic wounds. The ability of these devices to inhibit HNE was evaluated using porcine pancreatic elastase (PPE) solution as a model of wound exudates. The results obtained indicated that the level of PPE activity can be tuned by changing the organic solvent present on different protein microspheres. Moreover, these proteinaceous microspheres were shown to be important carriers of elastase inhibitors causing no cytotoxicity in human skin fibroblasts in vitro. These devices demonstrate an innovative way to control the imbalance of elastase/antielastase found in chronic wounds.

The entrapment of an anti-inflammatory drug, piroxicam, was also achieved, using BSA and HSA microspheres. ${ }^{70}$ The entrapment efficiency of piroxicam into BSA and HSA microspheres was assessed and shows that PVA promotes the increase of drug incorporation efficiency in both types of proteinaceous devices prepared $(\approx 80 \%$ with PVA and $\approx 50 \%$ without PVA). The work performed included the determination of the release kinetics of piroxicam from proteinaceous microspheres in the presence of protease, indicating an anomalous drug transport mechanism (diffusion and polymer degradation). In the presence of higher protease concentration, BSA microspheres exhibit case II transport, leading to zeroorder release (polymer degradation). The authors proved that the kinetics of piroxicam entrapped in BSA or HSA microspheres release mechanism is dependent on the protein and on protease concentration. Furthermore, these proteinaceous devices did not show cytotoxicity against human skin fibroblasts in vitro, for range concentrations below $300 \mathrm{mg} \mathrm{L}^{-1}$, greatly supporting their potential application in the treatment of inflammatory diseases. 
Suslick and co-workers ${ }^{56}$ reported on a noncovalent, electrostatic layer-by-layer (LBL) modification that successfully targets protein microspheres to the integrin receptors that are overexpressed in several tumor types. They determined the efficacy of the RGD-modified microspheres in tumor targeting by using HT29 tumor cells in vitro. HT29 cells are human colon tumor cells which are known to overexpress integrin receptors. For the targeting experiments, microspheres were synthesized with Nile red fluorescent dye in vegetable oil in their core. The fluorescence results demonstrate that binding of RGD-modified microspheres is increased relative to the unmodified ones. Suslick has found that these negatively charged vesicles are excellent templates for LBL electrostatic adhesion, which opens a new tool for both targeted imaging and targeted drug delivery.

Multilayer deposition of polyelectrolytes onto air-filled microbubbles is an attractive strategy to design targeted particles. Cavalieri et al. ${ }^{59}$ report the synthesis of stable and functional microbubbles, coated with chemically reduced lysozyme, using high-intensity ultrasound in aqueous solution. In order to demonstrate the possibility of surface functionalization of lysozyme microbubbles, which is of importance in targeted drug delivery, they adsorbed a polyelectrolyte on the surface of the microbubbles. Lysozyme air-filled microbubbles are positively charged colloidal particles and provide a good template for assembly of polyelectrolyte multilayer using the LBL approach. Two layers of poly(styrenesulfonate)/poly(allylamine hydrochloride) were assembled on the lysozyme shell, indicating the possibility of adsorbing potential drugs and/or biolabels on the surface of these microbubbles for therapeutic and diagnostic applications.

Another approach of proteinaceous microspheres is their application onto textile support. In fact, the prolonged contact time of a drug with a body tissue, through the use of wound dressings, can significantly improve the performance of many drugs. These improvements range from better treatment of local pathologies to improved drug bioavailability and controlled release to enhanced patient compliance. ${ }^{176}$ Furthermore, dressings that will deliver an active substance to a specific target site in a controlled fashion for a sustained period could help solve or minimize the noncompliance patients. In this highlight, the use of DS attached onto textiles-based wound dressings is being exploited for the treatment of several diseases.

There are a variety of methods for the attachment of the DS onto several dressings. The sonochemical method appears as one of the most effective methods, once that it is possible to produce and attach the microspheres to fibers by one-step reaction.

BSA and casein microspheres have been attached to cotton and polyester fabrics using sonochemical radiation. ${ }^{177}$ Proteinaceous microspheres bound to polyester remain linked to the fabric even after repeated washings in a washing machine, suggesting that these coated fibers can be used either for onetime application or for repeated use.

Gouveia ${ }^{178}$ also demonstrate the potentialities of sonochemical methodology to develop a coating process based on BSA/Lcysteine (L-Cys) microspheres on different textile materials, namely $100 \%$ of cotton, wool, polyester, polyamide, cellulose acetate, and viscose. The microspheres developed by this process evidence antimicrobial property by themselves due to the addition of L-Cys. The author performed the antibacterial assays against $S$. aureus and $K$. pneumonia. The results revealed the antibacterial effect of a BSA + L-Cys microsphere-coated cotton textile fabric, both for Gram-positive and -negative bacteria, by the inhibition zone located under the textile. Therefore, the antimicrobial functionalization of the fibers with $\mathrm{L}-\mathrm{Cys}$ microspheres is a promising new approach that can also diminish bacteria resistance.

Recently, it was reported the use of an anti-inflammatory drug, piroxicam, sonochemical entrapped on BSA microspheres and attached onto cotton and nonwoven gauzes by two different methodologies (incubation and sonochemical methodology). ${ }^{179}$ The authors proved that the highest release was achieved when the attachment process was performed by the sonochemical method. The short time treatment $(3 \mathrm{~min})$ improves the mass transport effects enhancing the microspheres attachment. The capacity of ultrasound to attach the microspheres to gauzes was made by one-step reaction, providing a reduction in the products consumption, shorter process time, and a greater uniformity of the treatment. Furthermore, the authors prove that the release of piroxicam entrapped in BSA microspheres was shown to be dependent on the gauzes structure, demonstrating a faster and higher concentration of piroxicam released when the proteinaceous microspheres were attached on nonwoven gauzes. This work shows the ability of the functionalized biomaterial to deliver the pharmaceutical agent.

The major advantages of the sonochemical methodology in comparison with other techniques that are commonly used to incorporate microspheres/microcapsules onto textile materials are the nontoxicity both to the potential users and to the environment and the possibility of being carried out in a simple step process with short reaction time and without using crosslinking agents such glutaraldehyde or epoxy resins that are normally required to produce microspheres or to bind them onto the textile materials.

\section{MAJOR REMARKS AND FUTURE OUTLOOK}

The rapidly developing field of nano- and microstructured synthesis constantly attracts new methods and solutions for further improving the process performance.

The usefulness of sonochemical synthesis as a synthetic tool resides in its versatility. In this review it was highlighted the use of ultrasound sources to produce different nano- and microparticles starting from phospholipids and polymeric based proteins. The progress achieved on the synthesis of lipidic and polymeric nano- and microstructures has been accompanied by the parallel exploitation of these materials in various fields, among them the controlled release. The sonochemical method has been further extended to the applications of these delivery devices designed to be textilebased wound dressings.

There are still some challenges left to be overcome for further development delivery-based platforms. The variety of natural proteins encourages us to explore more naturally existing proteins for versatile drug delivery, which can be prepared by the sonochemical method.

Future developments for delivery devices can focus on the enhanced site-specific drug delivery by using receptor-targeting ligands, improve sustained drug release rates with enhanced permeability and retention time, and minimize the undesirable side effects.

Furthermore, there is a demand to obtain preparation methods of the nano- and microparticles that are able to be reproducible on an industrial scale. 


\section{AUTHOR INFORMATION}

\section{Corresponding Author}

*E-mail: @det.uminho.pt. Tel: 00351253 510271. Fax: 00351 253510293.

\section{ACKNOWLEDGMENTS}

We acknowledge the financial support of European project Lidwine (Contract NMP2-CT-2006-026741) and to POPH/ FSE for cofinancing and FCT for fellowship SFRH/BPD/ $38939 / 2007$.

\section{REFERENCES}

(1) Barat, A.; Crane, M.; Ruskin, H. J. Quantitative Multi-Agent Models for Simulating Protein Release From PLGA Bioerodible Nanoand Microspheres. J. Pharm. Biomed. Anal. 2008, 48 (2), 361-368.

(2) Basinska, T. Hydrophilic Core-Shell Microspheres: A Suitable Support for Controlled Attachment of Proteins and Biomedical Diagnostics. Macromol. Biosci. 2005, 5, 1145-1168.

(3) Müller, R. H.; Mäder, K.; Gohla, S. Solid Lipid Nanoparticles (SLN) for Controlled Drug Delivery - A Review of the State of the Art. Eur. J. Pharm. Biopharm. 2000, 50 (1), 161-177.

(4) Torchilin, V. P. Targeted Polymeric Micelles for Delivery of Poorly Soluble Drugs. Cell. Mol. Life Sci. 2004, 61 (19), 2549-2559.

(5) Lasic, D. D. The Mechanism of Vesicle Formation. Biochem. J. 1988, 256 (1), 1-11.

(6) Svenson, S.; Tomalia, D. Dendrimers in Biomedical Applications - Reflections on the Field. Adv. Drug Delivery Rev. 2005, 57 (15), $2106-2129$

(7) Lensen, D.; Vriezema, D. M.; van Hest, J. C. M. Polymeric Microcapsules for Synthetic Applications. Macromol. Biosci. 2008, 8, 991-1005.

(8) Couvreur, P.; Vauthier, C. Nanotechnology: Intelligent Design to Treat Complex Disease. Pharm. Res. 2006, 23 (7), 1417-1450.

(9) Couvreur, P.; Gref, R.; Andrieux, K.; Malvy, C. Nanotechnologies for Drug Delivery: Application to Cancer and Autoimmune Diseases. Prog. Solid State Chem. 2006, 34 (2-4), 231-235.

(10) Jong, W. H. D.; Borm, P. J. Drug Delivery and Nanoparticles: Applications and Hazards. Int. J. Nanomed. 2008, 3 (2), 133-149.

(11) Suslick, K. S.; Price, G. J. Applications of Ultrasound to Materials Chemistry. Annu. Rev. Mater. Res. 1999, 29, 295-326.

(12) Mason, T. J.; Peters, D. Practical Sonochemistry: Uses and Applications of Ultrasound, 2nd ed.; Horwood Publishing: Chischester, 2002

(13) Shchukin, D. G.; Mohwald, H. Sonochemical Nanosynthesis at the Engineered Interface of a Cavitation Microbubble. Phys. Chem. Chem. Phys. 2006, 8 (30), 3496-3506.

(14) Mason, T. J. Advances in Sonochemistry; Jai Press Inc.: Stamford, CT, 1999; Vol. 5, p 325.

(15) Suslick, K. S.; Didenko, Y.; Fang, M. M.; Hyeon, T.; Kolbeck, K. J.; M., W. B. III; Mdleleni, M. M.; Wong, M. Acoustic Cavitation and its Chemical Consequences. Philos. Trans. R. Soc. London, A 1999, 357, $335-353$.

(16) Gandhi, K.; Kumar, R. Sonochemical reaction engineering. Sadhana 1994, 19 (6), 1055-1076.

(17) Suslick, K. S.; Crum, L. A. Sonochemistry and Sonoluminescence; Wiley-Interscience: New York, 1997; pp 271-281.

(18) Ashokkumar, M.; Lee, J.; Kentish, S.; Grieser, F. Bubbles in an Acoustic Field: An Overview. Ultrason. Sonochem. 2007, 14 (4), 470475.

(19) Gong, C.; Hart, D. P. Ultrasound Induced Cavitation and Sonochemical Yields. J. Acoust. Soc. Am. 1998, 104, 1-16.

(20) Rae, J.; Ashokkumar, M.; Eulaerts, O.; von Sonntag, C.; Reisse, J.; Grieser, F. Estimation of Ultrasound Induced Cavitation Bubble Temperatures in Aqueous Solutions. Ultrason. Sonochem. 2005, 12 (5), 325-329.

(21) Suslick, K. S. Applications of Ultrasound to Materials Chemistry. MRS Bull. 1995, 20, 29-34.
(22) Makino, K.; Mossoba, M. M.; Riesz, P. Chemical effects of ultrasound on aqueous solution. Formation of hydroxyl radicals and hydrogen atoms. J. Phys. Chem. 1983, 87, 1369-1377.

(23) Mason, T. J.; Lorimer, J. P.; Bates, D. M.; Zhao, Y. Dosimetry in Sonochemistry: The Use of Aqueous Terephthalate Ion as a Fluorescence Monitor. Ultrason. Sonochem. 1994, 1 (2), 91-95.

(24) Hart, E. J.; Henglein, A. Free radical and free Atom Reactions in the Sonolysis of Aqueous Iodide and Formate Solutions. J. Phys. Chem. 1985,

(25) Price, G.; Lenz, E. J. The Use of Dosimeters to Measure Radical Production in Aqueous Sonochemical Systems. Ultrasonics 1993, 31 (6), 451-455.

(26) Fang, X.; Mark, G.; von Sonntag, C. OH Radical Formation by Ultrasound in Aqueous Solutions. Part I: The Chemistry Underlying the Terephtalate Dosimeter. Ultrason. Sonochem. 1996, 3, 57-63.

(27) Bang, J. H.; Suslick, K. S. Applications of Ultrasound to the Synthesis of Nanostructured Materials. Adv. Mater. 2010, 22, 10391059 .

(28) Huang, C. Studies on Phosphatidylcholine Vesicles. Formation and Physical Characteristics. Biochemistry 1969, 8 (1), 344-52.

(29) Finer, E. G.; Flook, A. G.; Hauser, H. Mechanism of Sonication of Aqueous Egg Yolk Lecithin Dispersions and Nature of the Resultant Particles. Biochim. Biophys. Acta 1972, 260 (1), 49-58.

(30) Zasadzinski, J. A. Transmission Electron Microscopy Observations of Sonication-Induced Changes in Liposome Structure. Biophys. J. 1986, 49 (6), 1119-1130.

(31) New, R. R. C. Liposomes - A Practical Approach; Oxford University Press: New York, 1990; p 301.

(32) Almog, R.; Forward, R.; Samsonoff, C. Stability of Sonicated Aqueous Suspensions of Phospholipids Under Air. Chem. Phys. Lipids 1991, 60, 93-99.

(33) Lasic, D. D., Liposomes - from Physics to Applications; Elsevier: New York, 1993.

(34) Maulucci, G.; De Spirito, M.; Arcovito, G.; Boffi, F.; Castellano, A. C.; Briganti, G. Particle Size Distribution in DMPC Vesicles Solutions Undergoing Different Sonication Times. Biophys. J. 2005, 88 (5), 3545-3550.

(35) Woodbury, D. J.; Richardson, E. S.; Grigg, A. W.; Welling, R. D.; Knudson, B. H. Reducing Liposome Size with Ultrasound: Bimodal Size Distributions. J. Liposome Res. 2006, 16 (1), 57-80.

(36) Pereira-Lachataignerais, J.; Pons, R.; Panizza, P.; Courbin, L.; Rouch, J.; López, O. Study and Formation of Vesicle Systems with Low Polydispersity Index by Ultrasound Method. Chem. Phys. Lipids 2006, 140 (1-2), 88-97.

(37) Kim, S. H.; Haimovich-Caspi, L.; Omer, L.; Talmon, Y.; Franses, E. I. Effect of Sonication and Freezing-Thawing on the Aggregate Size and Dynamic Surface Tension of Aqueous DPPC Dispersions. J. Colloid Interface Sci. 2007, 311 (1), 217-227.

(38) Richardson, E. S.; Pitt, W. G.; Woodbury, D. J. The Role of Cavitation in Liposome Formation. Biophys. J. 2007, 93 (12), 41004107.

(39) Yamaguchi, T.; Nomura, M.; Matsuoka, T.; Koda, S. Effects of Frequency and Power of Ultrasound on the Size Reduction of Liposome. Chem. Phys. Lipids 2009, 160 (1), 58-62.

(40) Silva, R.; Ferreira, H.; Little, C.; Cavaco-Paulo, A. Effect of Ultrasound Parameters for Unilamellar Liposome Preparation. Ultrason. Sonochem. 2010, 17 (3), 628-632.

(41) Silva, R.; Little, C.; Ferreira, H.; Cavaco-Paulo, A. Incorporation of Peptides in Phospholipid Aggregates Using Ultrasound. Ultrason. Sonochem. 2008, 15, 1026-1032.

(42) Ramírez, R.; Martá, M.; Cavaco-Paulo, A.; Silva, R.; de la Maza, A.; Parra, J. L.; Coderch, L. Liposome Formation with Wool Lipid Extracts Rich in Ceramides. J. Liposome Res. 2009, 19 (1), 77-83.

(43) Mehnert, W.; Mäder, K. Solid lipid nanoparticles: Production, characterization and applications. Adv. Drug Delivery Rev. 2001, 47 (23), 165-196.

(44) Schwarz, C.; Mehnert, W. Freeze-drying of drug-free and drugloaded solid lipid nanoparticles (SLN). Int. J. Pharm. 1997, 157 (2), 171-179. 
(45) Suslick, K. S.; Grinstaff, M. W. Protein Microencapsulation of Nonaqueous Liquids. J. Am. Chem. Soc. 1990, 112, 7807-7809.

(46) Grinstaff, M. W.; Suslick, K. S. Air-filled Proteinaceous Microbubbles: Synthesis of an Echo-Contrast Agent. Chemistry 1991, 88 (17), 7708-7710.

(47) Grinstaff, M. W.; Suslick, K. S. Nonaqueous Liquid Filled Microcapsules. Polym. Prep. 1991, 32, 255.

(48) Suslick, K. S.; Grinstaff, M. W.; Kolbeck, K. J.; Wong, M. Characterization of Sonochemically Prepared Proteinaceous Microspheres. Ultrason. Sonochem. 1994, 1 (1), S65-S68.

(49) Wong, M.; Suslick, K. S. Sonochemically Produced Hemoglobin Microbubbles. Mater. Res. Soc. Symp. Proc. 1995, 372, 89.

(50) Avivi, S.; Felner, I.; Novik, I.; Gedanken, A. The Preparation of Magnetic Proteinaceous Microspheres Using The Sonochemical Method. Biochim. Biophys. Acta 2001, 1527 (3), 123-129.

(51) Makino, K.; Mizorogi, T.; Ando, S.; Tsukamoto, T.; Ohshima, H. Sonochemically Prepared Bovine Serum Albumin Microcapsules: Factors affecting The size Distribution and the Microencapsulation Yield. Colloids Surf., B 2001, 22 (3), 251-255.

(52) Avivi, S.; Gedanken, A. S-S bonds Are Not Required For The Sonochemical Formation of Proteinaceous Microspheres: The Case of Streptavidin. Biochem. J. 2002, 366 (3), 705-707.

(53) Makino, K.; Mizorogi, T.; Ando, S.; Tsukamoto, T.; Ohshima, H. Sustained Release of Hydrophobic Materials From Sonochemically Prepared Bovine Serum albumin Microcapsules. Colloids Surf., B 2002, 23 (1), 59-64.

(54) Avivi.; Nitzan, Y.; Dror, R.; Gedanken, A. An Easy Sonochemical Route for the Encapsulation of Tetracycline In Bovine Serum Albumin Microspheres. J. Am. Chem. Soc. 2003, 125 (51), 15712-15713.

(55) Avivi, S.; Gedanken, A. The Preparation of Avidin Microspheres Using the Sonochemical Method and the Interaction of the Microspheres with Biotin. Ultrason. Sonochem. 2005, 12 (5), 405-409.

(56) Toublan, F. J. J.; Boppart, S.; Suslick, K. S. Tumor Targeting by Surface-Modified Protein Microspheres. J. Am. Chem. Soc. 2006, 128, 3472-3473.

(57) Avivi, S.; Gedanken, A. Are Sonochemically Prepared AlphaAmylase Protein Microspheres Biologically Active? Ultrason. Sonochem. 2007, 14 (1), 1-5.

(58) Grinberg, O.; Hayun, M.; Sredni, B.; Gedanken, A. Characterization and Activity of Sonochemically-Prepared BSA Microspheres Containing Taxol - An Anticancer Drug. Ultrason. Sonochem. 2007, 14 (5), 661-666.

(59) Cavalieri, F.; Ashokkumar, M.; Grieser, F.; Caruso, F. Ultrasonic Synthesis of Stable, Functional Lysozyme Microbubbles. Langmuir 2008, 24 (18), 10078-10083.

(60) Han, Y.; Radziuk, D.; Shchukin, D.; Moehwald, H. Stability and Size Dependence of Protein Microspheres Prepared by Ultrasonication. J. Mater. Chem. 2008, 18 (42), 5162-5166.

(61) Grinberg, O.; Gedanken, A.; Patra, C. R.; Patra, S.; Mukherjee, P.; Mukhopadhyay, D. Sonochemically Prepared BSA Microspheres Containing Gemcitabine, And Their Potential Application in Renal Cancer Therapeutics. Acta Biomater. 2009, 5 (8), 3031-3037.

(62) Angel, U.; Matas, D.; Michaeli, S.; Cavaco-Paulo, A.; Gedanken, A. Microspheres of Mixed Proteins. Chem.-Eur. J. 2010, 16, 21082114

(63) Borodina, T.; Grigoriev, D.; Markvicheva, E.; Möhwald, H.; Shchukin, D. Vitamin E Microspheres Embedded Within a Biocompatible Film for Planar Delivery. Adv. Eng. Mater. 2010, n/ $\mathrm{a}-\mathrm{n} / \mathrm{a}$.

(64) Grinberg, O.; Gedanken, A. The Development and Characterization of Starch Microspheres Prepared by a Sonochemical Method for the Potential Drug Delivery of Insulin. Macromol. Chem. Phys. 2010, 211, 924-931.

(65) Zhou, M.; Leong, T. S. H.; Melino, S.; Cavalieri, F.; Kentish, S.; Ashokkumar, M. Sonochemical Synthesis of Liquid-Encapsulated Lysozyme Microspheres. Ultrason. Sonochem. 2010, 17 (2), 333-337.

(66) Silva, R.; Ferreira, H.; Araujo, R.; Azoia, N.; Rollet, A.; Angel, U.; Gomes, A.; Freddi, G.; Güebitz, G.; Gedanken, A.; Cavaco-Paulo,
A. Insights on the Mechanism of Protein Microspheres Formation 2011, submitted.

(67) Silva, R.; Ferreira, H.; Azoia, N.; Rollet, A.; Shimanovich, U.; Güebitz, G.; Gedanken, A.; Cavaco-Paulo, A. Mechanisms of the Formation of Proteinaceous Microspheres - Highlights from Peptide Size and Sequences 2011, submitted.

(68) Silva, R.; Fernandes, M.; Ferreira, H.; Donelli, I.; Freddi, G.; Artur, C.-P. Protein Disulfide Isomerase-Induced Refolding of Ribonuclease A Micropsheres 2011, submitted.

(69) Silva, R.; Ferreira, H.; Vasconcelos, A.; Gomes, A.; CavacoPaulo, A. Sonochemical Proteinaceous Devices for Wound Healing 2011, submitted.

(70) Silva, R.; Ferreira, H.; Carvalho, A.; Gomes, A.; Cavaco-Paulo, A. Protein Microspheres as Suitable Devices for Piroxicam Release 2011, submitted.

(71) Skirtenko, N.; Tzanov, T.; Gedanken, A.; Rahimipour, S. OneStep Preparation of Multifunctional Chitosan Microspheres by a Simple Sonochemical Method. Chem.-Eur. J. 2010, 16, 562-567.

(72) Teng, X. R.; Shchukin, D. G.; Mohwald, H. A Novel Drug Carrier: Lipophilic Drug-Loaded Polyglutamate/Polyelectrolyte Nanocontainers. Langmuir 2007, 24 (2), 383-389.

(73) Cavalieri, F.; El Hamassi, A.; Chiessi, E.; Paradossi, G.; Villa, R.; Zaffaroni, N. Tethering Functional Ligands onto Shell of Ultrasound Active Polymeric Microbubbles. Biomacromolecules 2006, 7 (2), 604611.

(74) Petrov, A. I.; Volodkin, D. V.; Sukhorukov, G. B. ProteinCalcium Carbonate Coprecipitation: A Tool for Protein Encapsulation. Biotechnol. Prog. 2005, 21, 918-925.

(75) Shchukin, D. G.; Köhler, K.; Möhwald, H.; Sukhorukov, G. B. Gas-Filled Polyelectrolyte Capsules. Angew. Chem. 2005, 44 (21), 3310-3314.

(76) Suslick, K. S.; Fang, M.; Hyeon, T. Sonochemical Synthesis of Iron Colloids. J. Am. Chem. Soc. 1996, 118 (47), 11960-11961.

(77) Wu, C.; Mosher, B. P.; Zeng, T. Rapid Synthesis of Gold and Platinum Nanoparticles Using Metal Displacement Reduction with Sonomechanical Assistance. Chem. Mater. 2006, 18 (13), 2925-2928.

(78) Suslick, K. S.; Hyeon, T.; Fang, M. Nanostructured Materials Generated by High-Intensity Ultrasound: Sonochemical Synthesis and Catalytic Studies. Chem. Mater. 1996, 8 (8), 2172-2179.

(79) Jeevanandam, P.; Koltypin, Y.; Gedanken, A. Synthesis of Nanosized $\alpha$-Nickel Hydroxide by a Sonochemical Method. Nano Lett. 2001, 1 (5), 263-266.

(80) Zhu, J.-J.; Wang, H.; Xu, S.; Chen, H.-Y. Sonochemical Method for the Preparation of Monodisperse Spherical and Rectangular Lead Selenide Nanoparticles. Langmuir 2002, 18 (8), 3306-3310.

(81) Gedanken, A. Using Sonochemistry for the Fabrication of Nanomaterials. Ultrason. Sonochem. 2004, 11 (2), 47-55.

(82) Zhu, Y.; Li, H.; Koltypin, Y.; Hacohen, Y. R.; Gedanken, A. Sonochemical Synthesis of Titania Whiskers and Nanotubes. Chem. Commun. 2001, 24, 2616-2617.

(83) Zhang, J.; Du, J.; Han, B.; Liu, Z.; Jiang, T.; Zhang, Z. Sonochemical Formation of Single-Crystalline Gold Nanobelts. Angew. Chem. 2006, 45 (7), 1116-1119.

(84) Zhou, S.-M.; Zhang, X.-H.; Meng, X.-M.; Fan, X.; Lee, S.-T.; $\mathrm{Wu}$, S.-K. Sonochemical Synthesis of Mass Single-Crystal PbS Nanobelts. J. Solid State Chem. 2005, 178 (1), 399-403.

(85) Li, C. P.; Teo, B. K.; Sun, X. H.; Wong, N. B.; Lee, S. T. Hydrocarbon and Carbon Nanostructures Produced by Sonochemical Reactions of Organic Solvents on Hydrogen-Passivated Silicon Nanowires under Ambient Conditions. Chem. Mater. 2005, 17 (23), $5780-5788$.

(86) Sun, X.-H.; Li, C.-P.; Wong, N.-B.; Lee, C.-S.; Lee, S.-T.; Teo, B.-K. Templating Effect of Hydrogen-Passivated Silicon Nanowires in the Production of Hydrocarbon Nanotubes and Nanoonions via Sonochemical Reactions with Common Organic Solvents under Ambient Conditions. J. Am. Chem. Soc. 2002, 124 (50), 14856-14857.

(87) Suslick, K. S.; Choe, S. B.; Cichowlas, A. A.; Grinstaff, M. W. Sonochemical Synthesis of Armorphous Iron. Nature 1991, 353, 414416. 
(88) Grinstaff, M. W.; Cichowlas, A. A.; Choe, S. B.; Suslick, K. S. Effect of Cavitation Conditions on Amorphous Metal Synthesis. Ultrasonics 1992, 30 (3), 168-172.

(89) Edwards, K. A.; Baeumner, A. J. Liposomes in analyses. Talanta 2006, 68, 1421-1431.

(90) Bangham, A. D.; Horne, R. W. Negative Staining of Phospholipids and their Structural Modification by Surface-Active Agents as Observed in the Electron Microscope. J. Mol. Biol. 1964, 8 (5), 660-668, , IN2-IN10.

(91) Gregoriadisbrenda, G.; Ryman, E. Liposomes as Carriers of Enzymes or Drugs: A New Approach to the Treatment of Storage Diseases. Biochem. J. 1971, 124, 58.

(92) Sharma, A.; Sharma, U. S. Liposomes in Drug Delivery: Progress and Limitation. Int. J. Pharm. 1997, 154, 123-140.

(93) Jones, M. N.; Chapman, D. Micelles, Monolayers and Biomembranes; John Wiley \& Sons, Ltd.: New York, 1996; Vol. 14, p 252.

(94) Florkin, M.; Stotz, E. H. Lipid Metabolism of Compreensive Biochemistry; Elsevier: New York, 1967; Vol. 18.

(95) Edwards, K. A.; Baeumner, A. J. Liposomes in Analyses. Talanta 2006, 68 (5), 1421-1431.

(96) Vemuri, S.; Rhodes, C. T. Preparation and Characterization of Liposomes as Therapeutic Delivery Systems: A Review. Pharm. Acta Helv. 1995, 70 (2), 95-111.

(97) Fendler, J. H. Membrane Mimetic Chemistry; John Wiley \& Sons, Inc.: New York, 1982.

(98) Hope, M. J.; Bally, M. B.; Webb, G.; Cullis, P. R. Production of Large Unilamellar Vesicles by a Rapid Extrusion Procedure. Characterization of Size Distribution, Trapped Volume and Ability to Maintain a Membrane Potential. Biochim. Biophys. Acta 1985, 812, $55-65$.

(99) Perkins, W. R.; Minchey, S. R.; Ahl, P. L.; Janoff, A. S. The Determination of Liposome Captured Volume. Chem. Phys. Lipids 1993, 64 (1-3), 197-217.

(100) Bangham, A. D.; Standish, M. M.; Watkins, J. C. Diffusion of Univalent Ions Across the Lamellae of Swollen Phospholipids. J. Mol. Biol. 1965, 13, 238

(101) Gómez-Hens, A.; Manuel Fernández-Romero, J. The Role of Liposomes in Analytical Processes. TrAC Trends Anal. Chem. 2005, 24 (1), 9-19.

(102) Hope, M. J.; Nayar, R.; Mayer, L. D.; Cullis, P. R. Reduction of Liposome Size and Preparation of Unilamellar Vesicles by Extrusion Techniques. In Liposome Technology; CRC Press, Inc.: Boca Raton, FL, 1993; Vol. I, pp 123-139.

(103) Brotchie, A.; Grieser, F.; Ashokkumar, M. Effect of Power and Frequency on Bubble-Size Distributions in Acoustic Cavitation. Phys. Rev. Lett. 2009, 102 (8), 084302.

(104) Kruus, P.; Burk, R. C.; Entezari, M. H.; Otson, R. Formation and Mechanical Stability of Phospholipids Vesicles. Membrane 1997, 17, 257-262.

(105) Rabinovich-Guilatt, L.; Dubernet, C.; Gaudin, K.; Lambert, G.; Couvreur, P.; Chaminade, P. Phospholipid Hydrolysis in a Pharmaceutical Emulsion Assessed by Physicochemical Parameters and New Analytical Method. Eur. J. Pharm. Biopharm. 2005, 61, 6976.

(106) Lee, C.; Barnett, J.; Reaven, P. D. Liposomes Enriched in Oleic Acid are Less Susceptible to Oxidation and have Less Proinflammatory Activity when Exposed to Oxidizing Conditions. J. Lipid Res. 1998, 39 (6), 1239-1247.

(107) Laguerre, M.; Lecomte, J.; Villeneuve, P. Evaluation of the Ability of Antioxidants to Counteract Lipid Oxidation: Existing Methods, New Trends and Challenges. Prog. Lipid Res. 2007, 46 (5), 244-282.

(108) Zuidam, N. J.; Gouw, H. K. M. E.; Barenholz, Y.; Crommelin, D. J. A. Physical (in) Stability of Liposomes upon Chemical Hydrolysis: The role of Lysophospholipids and Fatty Acids. Biochim. Biophys. Acta 1995, 1240 (1), 101-110.
(109) Zuidam, N. J.; Crommelin, D. J. A. Differential Scanning Calorimetric Analysis of Dipalmitoylphosphatidylcholine-Liposomes Upon Hydrolysis. Int. J. Pharm. 1995, 126 (1-2), 209-217.

(110) Heurtault, B.; Saulnier, P.; Pech, B.; Proust, J.-E.; Benoit, J.-P. Physico-Chemical Stability of Colloidal Lipid Particles. Biomaterials 2003, 24 (23), 4283-4300.

(111) Suntres, Z. E.; Omri, A. The Role of Liposomal Antioxidants in Oxidative Stress. In Nanocarrier Technologies: Frontiers of Nanotherapy; Mozafari, M. R., Ed.; Springer: Dordrecht, The Netherlands, 2006; p 221.

(112) Kates, M. Biology of halophilic bacteria, Part II. Cell. Mol. Life Sci. 1993, 49 (12), 1027-1036.

(113) Jones, M. The Surface Properties of Phospholipids Liposomes Systems and their Characterization. Adv. Colloid Interface Sci. 1995, 54, 93-128.

(114) Maurer, N.; Fenske, D. B.; Cullis, P. R. Developments in liposomal drug delivery systems. Expert Opin. Biol. Ther. 2001, 1 (6), 923-947.

(115) Gregoriadis, G. Engineering liposomes for drug delivery: progress and problems. Trends Biotechnol. 1995, 13 (12), 527-537.

(116) Ahsan, F.; Rivas, I. P.; Khan, M. A.; Torres Suárez, A. I. Targeting to macrophages: role of physicochemical properties of particulate carriers--liposomes and microspheres--on the phagocytosis by macrophages. J. Controlled Release 2002, 79 (1-3), 29-40.

(117) Woodle, M. C. Sterically Stabilized Liposome Therapeutics. Adv. Drug Delivery Rev. 1995, 16, 249-265.

(118) Senior, J.; Gregoriadis, G. Is Half-Life of Circulating Liposomes Determined by Changes in their Permeability? FEBS Lett. 1982, 145 (1), 109-114.

(119) Woodle, M. C.; Lasic, D. D. Sterically Stabilized Liposomes. Biochim. Biophys. Acta 1992, 1113, 171-199.

(120) Lasic, D. D. Sterically Stabilized Vesicles. Angew. Chem. 1994, 33 (17), 1685-1698.

(121) Bocca, C.; Caputo, O.; Cavalli, R.; Gabriel, L.; Miglietta, A.; Gasco, M. R. Phagocytic Uptake of Fluorescent Stealth and NonStealth Solid Lipid Nanoparticles. Int. J. Pharm. 1998, 175 (2), 185193.

(122) Gabizon, A.; Shmeeda, H.; Horowitz, A. T.; Zalipsky, S. Tumor Cell Targeting of Liposome-Entrapped Drugs with Phospholipid-Anchored Folic Acid-PEG Conjugates. Adv. Drug Delivery Rev. 2004, 56 (8), 1177-1192.

(123) Stella, B.; Arpicco, S.; Peracchia, M. T.; Desmaële, D.; Hoebeke, J.; Renoir, M.; D’Angelo, J.; Cattel, L.; Couvreur, P. Design of Folic Acid-Conjugated Nanoparticles for Drug Targeting. J. Pharm. Sci. 2000, 89 (11), 1452-1464.

(124) Joshi, R.; Adhikari, S.; Patro, B. S.; Chattopadhyay, S.; Mukherjee, T. Free Radical Scavenging Behavior of Folic Acid: Evidence for Possible Antioxidant Activity. Free Radical Biol. Med. 2001, 30 (12), 1390-1399.

(125) Ansell, S. M.; Harasym, T. O.; Tardi, P. G.; Buchkowsky, S. S.; Bally, M. B.; Cullis, P. R. Antibody Conjugation Methods Active Targeting Liposomes 2000, 25, 51-67.

(126) Matzku, S.; Krempel, H.; Weckenmann, H.-P.; Schirrmacher, V.; Sinn, H.; Stricker, H. Tumour Targeting with Antibody-Coupled Liposomes: Failure to Achieve Accumulation in Xenografts and Spontaneous Liver Metastases. Cancer Immunol. Immunother. 1990, 31 (5), 285-291.

(127) Immordino, M. L.; Dosio, F.; Cattel, L. Stealth Liposomes: Review of the Basic Science, Rationale, and Clinical Applications, Existing and Potential. Int. J. Nanomed. 2006, 1 (3), 297-315.

(128) Ranade, V. V.; Hollinger, M. A. Role of Polymers in Drug Delivery. In Drug Delivery Systems, 2nd ed.; CRC Press LLC: Boca Raton, FL, 2003.

(129) Antonietti, M.; Landfester, K. Polyreactions in Miniemulsions. Prog. Polym. Sci. 2002, 27 (4), 689-757.

(130) Asua, J. M. Miniemulsion polymerization. Prog. Polym. Sci. 2002, 27 (7), 1283-1346. 
(131) Xu, Y.; Du, Y. Effect of Molecular Structure of Chitosan on Protein Delivery Properties of Chitosan Nanoparticles. Int. J. Pharm. 2003, 250 (1), 215-226.

(132) Petsko, G. A.; Ringe, D. Protein Structure and Function; New Science Press: London, 2005.

(133) Weber, C.; Coester, C.; Kreuter, J.; Langer, K. Desolvation Process and Surface Characterisation of Protein Nanoparticles. Int. J. Pharm. 2000, 194 (1), 91-102.

(134) Suslick, K. (Champaign, IL); Toublan, F. J. (Urbana, IL); Boppart, S. A. (Champaign, IL); Marks, D. L. (Urbana, IL). Surface Modified Protein Microparticles, 2007.

(135) Maham, A.; Tang, Z.; Wu, H.; Wang, J.; Lin, Y. Protein-Based Nanomedicine Platforms for Drug Delivery. Small 2009, 5 (15), $1706-1721$.

(136) Müller, B. G.; Leuenberger, H.; Kissel, T. Albumin Nanospheres as Carriers for Passive Drug Targeting: An Optimized Manufacturing Technique. Pharm. Res. 1996, 13 (1), 32-37.

(137) Langer, K.; Balthasar, S.; Vogel, V.; Dinauer, N.; von Briesen, H.; Schubert, D. Optimization of the Preparation Process for Human Serum Albumin (HSA) Nanoparticles. Int. J. Pharm. 2003, 257 (1-2), $169-180$.

(138) Langer, K.; Anhorn, M. G.; Steinhauser, I.; Dreis, S.; Celebi, D.; Schrickel, N.; Faust, S.; Vogel, V. Human Serum Albumin (HSA) Nanoparticles: Reproducibility of Preparation Process and Kinetics of Enzymatic Degradation. Int. J. Pharm. 2008, 347 (1-2), 109-117.

(139) Wang, X.; Wenk, E.; Matsumoto, A.; Meinel, L.; Li, C.; Kaplan, D. L. Silk Microspheres for Encapsulation and Controlled Release. J. Controlled Release 2007, 117 (3), 360-370.

(140) Altman, G. H.; Diaz, F.; Jakuba, C.; Calabro, T.; Horan, R. L.; Chen, J.; Lu, H.; Richmond, J.; Kaplan, D. L. Silk-Based Biomaterials. Biomaterials 2003, 24 (3), 401-416.

(141) Latha, M. S.; Lal, A. V.; Kumary, T. V.; Sreekumar, R; Jayakrishnan, A. Progesterone Release from Glutaraldehyde CrossLinked Casein Microspheres: In vitro Studies and in vivo Response in Rabbits. Contraception 2000, 61 (5), 329-334.

(142) Latha, M. S.; Jayakrishnan, A.; New, A. Method for the Synthesis of Smooth, Round, Hydrophilic Protein Microspheres using Low Concentrations of Polymeric Dispersing Agents. J. Microencapsulation 1995, 12 (1), 7-12.

(143) Berthold, A.; Cremer, K.; Kreuter, J. Collagen Microparticles: Carriers for Glucocorticosteroids. Eur. J. Pharm. Biopharm. 1998, 45 (1), 23-29.

(144) Swatschek, D.; Schatton, W.; Müller, W. E. G.; Kreuter, J. Microparticles Derived from Marine Sponge Collagen (SCMPs): Preparation, Characterization and Suitability for Dermal Delivery of All-trans Retinol. Eur. J. Pharm. Biopharm. 2002, 54 (2), 125-133.

(145) Muvaffak, A.; Gurhan, I.; Hasirci, N. Prolonged Cytotoxic Effect of Colchicine Released From Biodegradable Microspheres. J. Biomed. Mater. Res., Part B 2004, 71B (2), 295-304.

(146) Young, S.; Wong, M.; Tabata, Y.; Mikos, A. G. Gelatin as a Delivery Vehicle for the Controlled Release of Bioactive Molecules. J. Controlled Release 2005, 109 (1-3), 256-274.

(147) Won, Y.-W.; Kim, Y.-H. Recombinant Human Gelatin Nanoparticles as a Protein Drug Carrier. J. Controlled Release 2008, 127 (2), 154-161.

(148) Kratz, F. Albumin as a Drug Carrier: Design of Prodrugs, Drug Conjugates and Nanoparticles. J. Controlled Release 2008, 132 (3), 171-183.

(149) Peters, T. J. Serum Albumin. Adv. Protein Chem. 1985, 37, $161-245$.

(150) Carter, D. C.; He, X. M.; Munson, S. H.; Twigg, P. D.; Gernert, K. M.; Broom, M. B.; Miller, T. Y. Three-Dimensional Structure of Human Serum Albumin. Science 1989, 244 (4909), 11951198.

(151) Carter, D. C.; Ho, J. X. Structure of Serum Albumin. Adv. Protein Chem. 1994, 45, 153-203.

(152) Fasano, M.; Curry, S.; Terreno, E.; Galliano, M.; Fanali, G.; Narciso, P.; Notari, S.; Ascenzi, P. The Extraordinary Ligand Binding
Properties of Human Serum Albumin. IUBMB Life 2005, 57 (12), 787-796.

(153) Bertucci, C.; Domenici, E. Reversible and Covalent Binding of Drugs to Human Serum Albumin: Methodological Approaches and Physiological Relevance. Curr. Med. Chem. 2002, 9, 1463-1481.

(154) Yampolskaya, G. P.; Tarasevich, B. N.; Elenskii, A. A. Secondary Structure of Globular Proteins in Adsorption Layers at the Solution-Air Interface by the Data of Fourier Transform IR Spectroscopy. Colloid J. 2005, 67 (3), 385-391.

(155) Scheffel, U.; Rhodes, B.; Natarajan, T. K.; Wagner, H. N. Albumin Microspheres for Study of the Reticuloendothelial System. J. Nucl. Med. 1972, 13 (7), 498-503.

(156) Zolle, I.; Hosain, F.; Rhodes, B.; Wagner, H. N. Human Serum Albumin Milimicrospheres for Studies Reticuloentothelial System. J. Nucl. Med. 1970, 11, 379-380.

(157) Anton, N.; Benoit, J.-P.; Saulnier, P. Design and Production of Nanoparticles Formulated from Nano-Emulsion Templates-A Review. J. Controlled Release 2008, 128 (3), 185-199.

(158) Nazarov, R.; Jin, H.-J.; Kaplan, D. L. Porous 3-D Scaffolds from Regenerated Silk Fibroin. Biomacromolecules 2004, 5 (3), 718726.

(159) Lotz, B.; Colonna Cesari, F. The Chemical Structure and the Crystalline Structures of Bombyx mori Silk Fibroin. Biochimie 1979, 61 (2), 205-214.

(160) Yamaguchi, K.; Kikuchi, Y.; Takagi, T.; Kikuchi, A.; Oyama, F.; Shimura, K.; Mizuno, S. Primary Structure of the Silk Fibroin Light Chain Determined by cDNA Sequencing and Peptide Analysis. J. Mol. Biol. 1989, 210 (1), 127-139.

(161) Zhou, P.; Li, G.; Shao, Z.; Pan, X.; Yu, T. Structure of Bombyx mori Silk Fibroin Based on the DFT Chemical Shift Calculation. J. Phys. Chem. B 2001, 105 (50), 12469-12476.

(162) Fontenot, K.; Schork, F. J. Sensitivities of Droplet Size and Stability in Monomeric Emulsions. Ind. Eng. Chem. Res. 1993, 32 (2), 373-385.

(163) Taylor, P. Ostwald Ripening in Emulsions. Colloids Surf., A 1995, 99 (2-3), 175-185.

(164) Feczkó, T.; Tóth, J.; Gyenis, J. Comparison of the Preparation of PLGA-BSA Nano- and Microparticles by PVA, Poloxamer and PVP. Colloids Surf., A 2008, 319 (1-3), 188-195.

(165) Zhou, F.; Zhou, R.; Hao, X.; Wu, X.; Rao, W.; Chen, Y.; Gao, D. Influences of Surfactant (PVA) Concentration and $\mathrm{pH}$ on the Preparation of Copper Nanoparticles by Electron Beam Irradiation. Radiat. Phys. Chem. 2008, 77 (2), 169-173.

(166) Mu, L.; Seow, P. H. Application of TPGS in Polymeric Nanoparticulate Drug Delivery System. Colloids Surf., B 2006, 47 (1), 90-97.

(167) Cohen-Sela, E.; Chorny, M.; Koroukhov, N.; Danenberg, H. D.; Golomb, G.; New Double, A. Emulsion Solvent Diffusion Technique for Encapsulating Hydrophilic Molecules in PLGA Nanoparticles. J. Controlled Release 2009, 133 (2), 90-95.

(168) Lee, J.; Lee, S.-J.; Choi, J.-Y.; Yoo, J. Y.; Ahn, C.-H. Amphiphilic Amino Acid Copolymers as Stabilizers for the Preparation of Nanocrystal Dispersion. Eur. J. Pharm. Sci. 2005, 24 (5), 441-449.

(169) Hans, M. L.; Lowman, A. M. Biodegradable Nanoparticles for Drug Delivery and Targeting. Curr. Opin. Solid State Mater. Sci. 2002, 6 (4), 319-327.

(170) Lee, T. M.; Oldenburg, A. L.; Sitafalwalla, S.; Marks, D. L.; Luo, W.; Toublan, F. J.-J.; Suslick, K. S.; Boppart, S. A. Engineered Microsphere Contrast Agents for Optical Coherence Tomography. Opt. Lett. 2003, 28 (17), 1546-1548.

(171) Thassu, D.; Pathak, Y.; Deleers, M. Nanoparticulate DrugDelivery Systems: An Overview; Informa Healthcare USA, Inc.: New York, 2007; Vol. 166, p 382.

(172) Langer, R.; Peppas, N. A. Advances in Biomaterials, Drug Delivery, and Bionanotechnology. AIChE J. 2003, 49 (12), 29903006.

(173) Chellat, F.; Tabrizian, M.; Dumitriu, S.; Chornet, E.; Rivard, C. H.; Yahia, L. H. Study of Biodegradation Behavior of Chitosan- 
Xanthan Microspheres in Simulated Physiological Media. J. Biomed. Mater. Res. 2000, 53 (5), 592-599.

(174) Grassi, M.; Grassi, G. Mathematical Modelling and Controlled Drug Delivery: Matrix Systems. Curr. Drug Delivery 2005, 2, 97-116.

(175) Grigoriev, D.; Miller, R.; Shchukin, D.; Möhwald, H. Interfacial Assembly of Partially Hydrophobic Silica Nanoparticles Induced by Ultrasonic Treatment. Small 2007, 3 (4), 665-671.

(176) Boateng, J. S.; Matthews, K. H.; Stevens, H. N. E.; Eccleston, G. M. Wound Healing Dressings and Drug Delivery Systems: A Review. J. Pharm. Sci. 2008, 97, 2892-2923.

(177) Angel, U.; Silva, C. M.; Cavaco-Paulo, A.; Gedanken, A. Attaching Different Kinds of Proteinaceous Nanospheres to a Variety of Fabrics Using Ultrasound Radiation. Isr. J. Chem. 2010, 50, 524529.

(178) Gouveia, I. C. Synthesis and Characterization of a Microsphere-Based Coating for Textiles with Potential as an In Situ Bioactive Delivery Dystem. Polym. Adv. Technol 2010, .

(179) Silva, R.; Ferreira, H.; Cavaco-Paulo, A. Cotton and Nonwoven Gauzes Bandages: A Support for Proteinaceous Microspheres 2011, submitted. 